\title{
Run for your life: Can exercise be used to effectively target GLUT4 in diabetic cardiac disease?
}

\author{
Peter R.T. Bowman ${ }^{1}$, Godfrey L. Smith ${ }^{2}$, Gwyn W Gould ${ }^{\text {Corresp. } 1}$ \\ ${ }^{1}$ Strathclyde Institute of Pharmacy and Biomedical Sciences, University of Strathclyde, Glasgow, United Kingdom \\ 2 Institute of Cardiovascular and Medical Sciences, University of Glasgow, Glasgow, United Kingdom \\ Corresponding Author: Gwyn W Gould \\ Email address: gwyn.gould@strath.ac.uk
}

The global incidence, associated mortality rates and economic burden of diabetes are now such that it is considered one of the most pressing worldwide public health challenges.

Considerable research is now devoted to better understanding the mechanisms underlying the onset and progression of this disease, with an ultimate aim of improving the array of available preventive and therapeutic interventions. One area of particular unmet clinical need is the significantly elevated rate of cardiomyopathy in diabetic patients, which in part contributes to cardiovascular disease being the primary cause of premature death in this population. This review will first consider the role of metabolism and more specifically the insulin sensitive glucose transporter GLUT4 in diabetic cardiac disease, before addressing how we may use exercise to intervene in order to beneficially impact key functional clinical outcomes. 
1 Run for your life: Can exercise be used to effectively target GLUT4 in diabetic cardiac 2 disease?

Peter R.T. Bowman ${ }^{1}$, Godfrey L. Smith² and Gwyn W. Gould ${ }^{1}$

1Strathclyde Institute of Pharmacy and Biomedical Sciences, University of Strathclyde.

${ }^{2}$ Institute of Cardiovascular and Medical Sciences, College of Medical, Veterinary and Life

8 Sciences, University of Glasgow

Correspondence: gwyn.gould@strath.ac.uk or godfrey.smith@glasgow.ac.uk

\section{Abstract}

The global incidence, associated mortality rates and economic burden of diabetes are now such that it is considered one of the most pressing worldwide public health challenges. Considerable research is now devoted to better understanding the mechanisms underlying the onset and progression of this disease, with an ultimate aim of improving the array of available preventive and therapeutic interventions. One area of particular unmet clinical need is the significantly elevated rate of cardiomyopathy in diabetic patients, which in part contributes to cardiovascular disease being the primary cause of premature death in this population. This review will first consider the role of metabolism and more specifically the insulin sensitive glucose transporter GLUT4 in diabetic cardiac disease, before addressing how we may use exercise to intervene in order to beneficially impact key functional clinical outcomes.

\section{Introduction - Identifying the heart of the issue}

Diabetes is defined clinically by a fasting blood glucose value of $>7 \mathrm{mM}$, or fasting $\mathrm{HbA} 1 \mathrm{c}$ level $>6.5 \%$, predominantly due to peripheral insulin resistance (type 2 diabetes; T2D) or insufficient pancreatic insulin production (type 1 diabetes; T1D). The primary consequence of chronic hyperglycaemia is vascular degeneration (Dal Canto et al., 2019), which accounts for most common complications of diabetes e.g. diabetic retinopathy, diabetic foot and myocardial infarction (MI). Resulting increased blood pressure and coronary artery disease may also overload the heart and lead to the development of cardiac failure.

In 1972 a post-mortem of 4 diabetic patients identified cardiac failure in the absence of vascular disease, indicating for the first time that diabetes may directly impair cardiac structure and function (Rubler et al., 1972). This phenomenon is now referred to as diabetic cardiomyopathy (DCM), which first presents as an impairment in diastolic function early after the onset of diabetes. Early diastolic dysfunction has been repeatedly demonstrated in cohorts of asymptomatic diabetic patients using several echocardiographic parameters, primarily related to transmitral blood flow and myocardial tissue movement velocities during early and late diastole (Nicolino et al., 1995; Di Bonito et al., 1996; Poirier et al., 2001; Poulsen et al., 2010). Impaired relaxation of the ventricular wall is likely to delay early diastolic filling and therefore increase the contribution of atrial contraction mediated blood flow to ensure sufficient ventricular filling. If left 
41 unabated, major structural changes and systolic dysfunction develop and drive progression of

42 DCM towards heart failure (Bell, 2003).

43 The estimated prevalence of DCM varies, largely due to the sensitivity of the detection system

44 and criteria utilised. Boyer et al. demonstrated that within a population of asymptomatic

45 diabetics conventional Doppler echocardiography detected diastolic dysfunction in $46 \%$ of

46 individuals, whereas this increased to $63 \%$ using tissue Doppler imaging and $75 \%$ with a

47 combined approach (Boyer et al., 2004). The high prevalence and potentially severe life limiting

48 consequences of this condition coupled with a lack of specific treatment options makes this an

49 area of urgent unmet clinical need.

50 The pathophysiological mechanisms associated with DCM are complex, both in isolation and in

51 the way that they interact with and amplify one another via a myriad of signalling pathways (Jia,

52 Hill \& Sowers, 2018). Factors including activation of the renin-angiotensin and sympathetic

53 nervous systems, inflammation, oxidative and endoplasmic reticulum stress and increased

54 production of advanced glycation end products (AGEs) have all been cited (Figure 1). Importantly, many of these are secondary factors. While important contributors to disease progression, they are probably consequences of earlier events. These issues are worthy of review in their own right; however, here we will focus on key early instigators of DCM that arguably have the most potentially powerful disease modifying capacity e.g. metabolic changes linked to the glucose transporter GLUT4. We will then consider whether lessons from exercise physiology could offer a useful mechanism for treatment of DCM. This review is aimed at those with an interest in cardiovascular disease, exercise physiology and the metabolic basis of heart disease

\section{Survey methodology}

We conducted a literature search using combinations of key words (e.g. GLUT4 and diabetic cardiomyopathy) and ad hoc searches as required, using PubMed, MedLine or Web of Science providing an objective subject coverage. We selected articles in English and based on our subjective valuation of the work. This is therefore a comprehensive but not exhaustive review.

\section{The pathophysiology of diabetic cardiomyopathy}

Cardiac structure and function are intimately linked.A key facet of DCM is the onset of pathological left ventricular hypertrophy; however, it is important to note that often diastolic dysfunction is detected in diabetic human patients with no corresponding structural abnormalities(Schannwell et al., 2002). Additionally, whilst systemic hyperglycaemia is a fundamental feature of DCM (and diabetes in general), evidence from rodent models of diabetes indicates that cardiac specific insulin resistance is one of the earliest detectable pathological events, prior to the deterioration of cardiac function (Park et al., 2005). This suggests that intrinsic alterations within the myocardium may initiate DCM prior to manifestation of systemic insulin resistance. This may therefore arise before external (consequential or compensatory) factors drive disease progression. At a functional level, this points towards deficits in cardiomyocyte excitation contraction coupling [for a detailed review of this process see (Bers,

82 2002)]. Indeed, evidence from rodent models of DCM has established impaired cardiomyocyte 
83 calcium handling as a primary limitation (Belke \& Dillmann, 2004; Pereira et al., 2006; Stølen et

84 al., 2009). Studies of T2D patients have hinted at similar deficits (Lamberts et al., 2014; Daniels 85 et al., 2015).

86 Cardiac excitation contraction coupling is an energy intensive process dependent upon ATP

87 availability. Cardiomyocyte and therefore cardiac contraction and relaxation are intimately linked 88 to metabolic capacity. Normally, mitochondrial ATP production is generally matched by cellular

89 ATP consumption, which is largely accounted for by myosin ATPase and SERCA. The Creatine

90 Phosphate shuttle ensures high-energy phosphate delivery from mitochondria to cellular

91 ATPases as well as acting as a buffer for ATP during rapid increases in consumption / demand

92 that accompany increased workload e.g. during exercise (Elliott, Smith \& Allen, 1994). This

93 buffer function allows for the lag in the response of aerobic glycolysis to match ATP production

94 with demand and thus prevents the fall in local ATP concentration; however this occurs at the

95 expense of reduced cytoplasmic creatine phosphate ( $\mathrm{CrP})$ and raised inorganic phosphate

96 levels (Elliott, Smith \& Allen, 1994). T2D has been linked to cardiac mitochondrial dysfunction

97 that manifests as lowered intracellular CrP levels in T2D hearts (Bashir, Coggan \& Gropler,

98 2015). This adaptation does not appear to reduce glycolytic flux but lowered CrP/ATP ratios are

99 known to reduce contractile force and this metabolic mechanism may be an important

100 component of DCM.

101 As will be explained and explored further below, there is strong evidence that pathological

102 metabolic disturbances of the heart are the fundamental event initiating DCM (Lai et al., 2014;

103 Ritterhoff \& Tian, 2017; Karwi et al., 2018; Tan et al., 2020). Indeed, many would argue that

104 metabolic perturbations precede functional changes in many examples of cardiac malfunction. A

105 striking example is provided by recent work showing that levels of the mitochondrial pyruvate

106 carrier mediates pathological cardiac hypertrophy in human heart, and mouse knockout of

107 cardiomyocyte mitochondrial pyruvate carriers resulted in cardiac hypertrophy and reduced

108 survival (Fernandez-Caggiano et al., 2020). Hence, we focus the remainder of this review on

109 cardiac metabolism and substrate use as our thesis is that alterations in metabolism and

110 substrate use may be key aetiological factors in the development of DCM.

\section{The role of sugar and fat in a healthy heart}

112 Cardiac metabolism is classically characterised by the predominant use of fatty acids (FA) as a

113 metabolic substrate (Ritterhoff \& Tian, 2017; Kerr, Dodd \& Heather, 2017; Abel, 2018). These

114 are primarily transported into the cell via the transporter CD36 (Son et al., 2018), and

115 subsequently into mitochondria via carnitine palmitoyltransferase (CPT-1) where they undergo

116 beta-oxidation (Brown et al., 1995; Kim \& Dyck, 2016)(see Figure 2). Fat is an excellent fuel

117 source when considering the molecules of ATP generated per gram, thus making it particularly

118 suitable for powering the indefinite contractile activity of the heart. Under normal conditions

119 there is limited cardiac storage of fat because - as is the case for most organs - excessive

120 accumulation of triglycerides and associated metabolites from incomplete FA oxidation is

121 associated with lipotoxicity (D'Souza, Nzirorera \& Kienesberger, 2016). It is well known that

122 increasing fatty acid availability to the heart results in a marked inhibition of glucose oxidation

123 via the glucose/fatty acid cycle (Shipp, Opie \& Challoner, 1961; Randle et al., 1963; Hue \&

124 Taegtmeyer, 2009). However other additional mechanisms may be at play which are discussed

125 further below. 
126 Whilst, fat is undoubtedly an important fuel source for the heart, the ability to rapidly switch

127 between several metabolic substrates is essential to meet ATP demands in the face of varying

128 environmental conditions. Therefore, cardiac metabolism is actually best characterised as being

129 FA predominant but highly flexible (Ritterhoff \& Tian, 2017). The second major cardiac

130 metabolic substrate is glucose, which provides a more rapid source of ATP at a lower oxygen

131 cost (Abel, 2004; Doenst, Nguyen \& Abel, 2013). Although fatty acids are an abundant energy

132 source for the heart, the ATP produced per $O$ consumed is less efficient than for glucose

133 (Lopaschuk et al., 2010; Lopaschuk \& Ussher, 2016). Despite glucose metabolism providing

134 less ATP for the heart daily, defects in this may be of critical importance to DCM (Figure 2).

135 Hence, it is important that the role of glucose (both metabolism and transport) is carefully

136 considered.

137 The facilitated diffusion of glucose into target cells can occur via several isoforms of the GLUT

138 transporter family. Comprising 14 members, coded for by the SLC2 genes and at around 500

139 amino acids in length, each isoform is primarily distinguished by its substrate specificity (some

140 transport other hexoses such as fructose), rate of activity and tissue localisation (Mueckler \&

141 Thorens, 2013). In skeletal muscle and the heart, the 2 key transporters are GLUT1 and

142 GLUT4. During foetal development glucose is the predominant substrate and GLUT1 is

143 abundantly expressed in order to facilitate the sustained rapid uptake required to support

144 physiological development at this stage (Santalucía et al., 1992). Postnatally, upregulation of

145 GLUT4 and reduced GLUT1 content are observed, in association with levels of the thyroid

146 hormone $\mathrm{T}_{3}$ (Castelló et al., 1994). Despite this, GLUT1 continues to strongly influence basal

147 cardiac glucose uptake (Kraegen et al., 1993). GLUT1 is implicated in the pathogenesis of

148 diabetes, as reduced expression is associated with decreased basal skeletal muscle glucose

149 uptake in human diabetic patients. (Ciaraldi et al., 2005). However, by far the most important

150 transporter in cardiac glucose metabolism, overall function and disease is GLUT4.

151 GLUT4 mediates the regulation of glucose uptake by insulin sensitive tissues - predominantly

152 muscle and fat. Under resting conditions, GLUT4 is sequestered intracellularly in specialised

153 GLUT4 containing insulin responsive vesicles (IRVs; see Figure 2) (Gould, Brodsky \& Bryant,

154 2020). Post-prandial elevations in blood glucose concentration are sensed and then responded

155 to by the pancreas through increased release of insulin. Insulin binds to its receptor on

156 myocytes and adipocytes and in turn activates PI3K-Akt dependent and APS dependent

157 pathways (Leto \& Saltiel, 2012). These signalling networks ultimately result in the activation of

158 effector proteins that facilitate IRV trafficking to the plasma membrane (PM; Figure 2). These

159 effectors include the Myo1C motor protein that powers GLUT4 translocation, the exocyst

160 complex that tethers IRVs at the PM and the SNARE proteins that facilitate the fusion of these

161 opposing membranes (Gould, Brodsky \& Bryant, 2020). GLUT4 is unique in this mode of

162 regulation.

163 GLUT4 is essential in matching glucose supply and demand in the tissues where it is needed

164 most, and, therefore, also in the regulation of circulating blood glucose levels. The critical role of

165 this protein is underscored by findings that muscular insulin sensitivity is strongly correlated to

166 GLUT4 protein content (Kraegen et al., 1993), impaired insulin stimulated GLUT4 PM trafficking

167 in the skeletal muscle of T2D is the primary defect defining this disease (Garvey et al., 1998; 
168 Gould, Brodsky \& Bryant, 2020) and that GLUT4 protein overexpression preserves systemic 169 insulin sensitivity in a commonly employed mouse model of diabetes (Atkinson et al., 2013).

170 A second potent stimulus to enhance skeletal and cardiac muscle glucose uptake is contraction,

171 i.e. exercise (Richter \& Hargreaves, 2013; Richter, 2020). As outlined previously, excitation

172 contraction coupling is an energy intensive process and requires increased oxidation of glucose

173 to maintain a rapid supply of ATP under higher external workloads. Whilst this also requires

174 increased cell surface GLUT4 levels (Figure 2), aspects of contraction mediated GLUT4

175 trafficking appear distinct (Wojtaszewski et al., 2000; Richter \& Hargreaves, 2013; McConell et

176 al., 2020). For example, the stimuli initiating this process are multifaceted and include a change

177 in intracellular energy status (ATP:ADP ratio) leading to AMPK activation and mechanical stress

178 sensitive mechanisms activating the GTPase Rac1, which controls the remodelling of the

179 cytoskeleton required for vesicle translocation (O'Neill et al., 2011; Luiken, Glatz \& Neumann,

180 2015; Sylow et al., 2017). Further, there is evidence that increased PM GLUT4 levels in the

181 heart are facilitated by distinct SNARE proteins when stimulated by contraction versus insulin

182 (Schwenk et al., 2010) consistent with the notion that insulin and exercise recruit distinct

183 intracellular pools of GLUT4 (Richter \& Hargreaves, 2013). These observations in part explain

184 why contraction mediated glucose uptake is unaffected by insulin resistance (Wheatley et al.,

185 2004).

186 Hence, we posit that GLUT4 provides a crossover between metabolic and contractile regulation

187 of skeletal / cardiac metabolism. This is particularly interesting because DCM is a disease of

188 cardiac contractile deficit, with potential metabolic origins. As noted above, mitochondrial

189 dysfunction in T2D heart has been reported which manifests as lowered CrP levels (Bashir,

190 Coggan \& Gropler, 2015). It has been proposed that cardiac AMP-activated protein kinase

191 (AMPK) is regulated by creatine phosphate:creatine ratios in a similar way to ATP:AMP in

192 skeletal muscle - therefore when creatine phosphate levels are low, AMPK is activated

193 (Ponticos et al., 1998). AMPK activation in the heart increases glucose utilisation through

194 increased GLUT4 (Glatz et al., 2020)and stimulation of phosphofructokinase (Lefebvre et al

195 1996), arguing that increased CrP would attenuate glycolysis. Furthermore AMPK activators

196 increase creatine uptake into cardiomyocytes (Darrabie et al., 2011; Santacruz et al., 2017),

197 which would indicate that when glucose metabolism is low and ATP synthesis is low, increased

198 creatine uptake improves the likelihood of storing ATP as CrP. Such data would suggest that

199 glucose metabolism can influence creatine:phosphocreatine levels in cardiomyocytes (Ritterhoff

200 \& Tian, 2017; Glatz et al., 2020) and further reveal the metabolic importance of glucose

201 transport in cardiac metabolism.

202

203 Metabolic characterisation of the diabetic heart - linking metabolism to cardiac function

204 Magnetic resonance (MR) imaging has been used to demonstrate the presence of cardiac

205 diastolic dysfunction in asymptomatic diabetic individuals versus control subjects, despite

206 normal systolic function and left ventricular mass (Diamant et al., 2003). MR spectroscopy

207 revealed a significant association of this impairment with a reduction in the PCr:ATP ratio,

208 indicative of limitations in metabolic function (Abdurrachim \& Prompers, 2018). While the

209 association between PCr:ATP and cardiac function has been questioned (Cao et al., 2020), 
210 these findings were replicated in a separate study, which correlated this reduction in PCr:ATP

211 with circulating free fatty acid (FFA) concentration (Scheuermann-Freestone et al., 2003).

212 Increased FFA concentrations are expected in diabetic patients because obesity is one of the

213 major risk factors for this disease. Accordingly, due to an excessive FFA availability that

214 exceeds oxidation requirements or perhaps even capabilities, a key early marker of the diabetic

215 heart is increased triglyceride accumulation (McGavock et al., 2007). In a cohort of middle-aged

216 diabetic men, increased cardiac triglyceride content measured via MR spectroscopy was

217 significantly associated with an impaired cardiac E/A ratio (a marker of diastolic function)

218 (Rijzewijk et al., 2008). This association (independent of other relevant variables) has also been

219 demonstrated in non-diabetic groups, such as obese insulin-resistant women and otherwise

220 healthy aging men (van der Meer et al., 2008; Utz et al., 2011). Furthermore, a reduction in

221 myocardial triglyceride content in response to a weight loss intervention was associated with

222 improved cardiac diastolic function in diabetic individuals (Hammer et al., 2008). Taken

223 together, this suggests that accumulation of FFA in the heart may be a critical factor that impairs

224 metabolic ATP production and is a crucial instigator of DCM.

225

226

227

228

229

230

231

232

233

234

235

236

237

238

239

240

241

242

243

244

245

246

247

248

249

250

251

252

It is possible that the toxic metabolic effects of cardiac FFA accumulation are indirect. Skeletal muscle insulin resistance is the hallmark of diabetes, however there is also an abundance of evidence demonstrating myocardial insulin resistance and reduced glucose uptake in human diabetic patients (lozzo et al., 2002a; Dutka et al., 2006; Hu et al., 2018). This is generally demonstrated using positron emission tomography imaging of a radiolabelled glucose analogue that is infused during a euglycemic-hyperinsulinemic clamp. This reduction in cardiac glucose uptake has been demonstrated independent of any limitation in cardiac blood flow, although there is evidence that relative regional perfusion may be altered (lozzo et al., 2002b). Reduced glucose uptake could have significant consequences for cardiac metabolism and therefore performance due to the aforementioned rapid flux and oxygen efficient generation of ATP via glucose metabolism, particularly in the presence of subclinical cardiovascular stress (likely in patients with diabetes).

As will be explored below, the exact cause of insulin resistance is unclear but may be related to the accumulation of toxic lipid metabolites such as diacylglycerol (DAG), consequent to excessive FFA uptake. Therefore it could be that insulin resistance, at least in part, explains the association of increased cardiac triglyceride content with impaired diastolic function. Consistent with this idea, Rijzewijk et al. demonstrated that in T2D patients, increased cardiac FFA uptake and metabolism coincide with impaired glucose uptake and a reduced E/A ratio (Rijzewijk et al., 2009). Data from animal models confirms that manipulation of circulating FFA levels strongly influences both myocardial triglyceride accumulation and glucose uptake, and also that upregulation of CD36 localisation at the cell surface may facilitate this enhanced FFA entry (Coort et al., 2004; Ouwens et al., 2007; Guzzardi et al., 2014). Interestingly, thiazolidinediones such as pioglitazone have been shown to increase cardiac glucose uptake and improve cardiac diastolic function in diabetic patients, with no reported effect upon FFA uptake (von Bibra et al., 2008; van der Meer et al., 2009). This could imply that restoring insulin stimulated GLUT4 mediated glucose uptake is of primary importance in the diabetic heart.

The evidence discussed so far, predominantly studying asymptomatic T2D individuals, allows us to create logical associations and derive an evidence-based theory regarding the early 
253 pathological mechanisms driving DCM. Excessive FFA uptake and therefore accumulation may

254 lead to insulin resistance and starve the heart of the glucose that it needs to rapidly and

255

256

257

258

259

260

261

262

263

264

265

266

267

268

269

270

271

272

273

274

275

276

277

278

279

280

281

282

283

284

285

286

287

288

289

290

291

292

293

294

295 efficiently generate the ATP that powers excitation contraction coupling. The relatively smaller contribution of glucose to total cardiac metabolism under normal conditions does not diminish its functional importance. However, it is important not to overstate the strength of evidence that we currently have. Human based studies in this field will always face issues with confounding variables (e.g. patient characteristics) and the depth to which investigative techniques can probe subcellular cardiac physiology. Therefore, we must take the principles derived from this research and apply them to credible animal models that represent the human condition as closely as possible. This allows us to perform more invasive manipulative studies and explore these proposed mechanisms further, in the ultimate pursuit of identifying key therapeutic targets.

We suggest three mechanisms that may link impaired metabolism to diastolic dysfunction (Figure 3).

The first mechanism may involve a direct lipotoxic effect of FFA. Pharmacological inhibition of FA oxidation primarily through reduced CPT-1 mediated mitochondrial uptake was found to increase SERCA expression and ATP availability and ultimately improve cardiac function in diabetic rat hearts (Sharma et al., 2008). However, studies like this are difficult to interpret because a corresponding increase in glucose oxidation was also recorded.

Generally, lipotoxicity is thought to be mediated through FFA derivatives such as DAG or ceramide, which accumulate in diabetic muscle (Itani et al., 2002; Adams et al., 2004). Therefore, it is useful to probe the possible roles of these molecules in DCM. Accordingly, high fat diet fed rodent models of DCM exhibit impaired cardiac efficiency, which can be ameliorated via pharmacological or genetic inhibition of the mitochondrial uncoupling protein UCP3 (Cole et al., 2011; Boudina et al., 2012). Furthermore, mitochondrial uncoupling was directly demonstrated in mitochondrial preparations isolated from $d b / d b$ mouse hearts (Boudina et al., 2007). UCPs facilitate the movement of protons across the inner mitochondrial membrane without activating ATP synthase, and its upregulation in the diabetic rat heart was found to be regulated by protein kinase $C$ (Arikawa et al., 2007), a key downstream target of DAG. The potential translational significance of this link is enhanced by the observation that in non-diabetic human patients undergoing a cardiac procedure, increased circulating levels of FFA were associated with increased cardiac UCP2 and UCP3 expression and decreased expression of GLUT4, driving energy deficiency (Murray et al., 2004). Murray et al propose that increased mitochondrial UCP expression drives lowering myocardial energy as a result of collapsed proton-gradients across the mitochondria, explaining why cardiac PCr/ATP ratio is negatively correlated with plasma free fatty acids. This is exacerbated by reduced GLUT4 levels, creating an energy deficient myocardium which is highly likely to contribute towards diastolic dysfunction. The impact of GLUT4 levels on PCr/ATP ratio has yet to be defined in cardiac tissue, but transgenic animals offer a potentially useful means to investigate this question.

A second mechanism could be via impaired signalling pathways from the insulin receptor which may link insulin resistance in DCM with impaired cardiomyocyte function. Impaired activation of proximal insulin signalling cascades are consistently reported in diabetic animal models (Ouwens et al., 2005; Deng et al., 2007). Cardiomyocyte specific knock out of the insulin

PeerJ reviewing PDF | (2021:01:56957:1:1:NEW 15 Apr 2021) 
296

297

298

299

300

301

302

303

304

305

306

307

308

309

310

311

312

313

314

315

316

317

318

319

320

321

322

323

324

325

326

327

328

329

330

331

332

333

334

335

336

337

receptor and therefore an inability to activate downstream signalling cascades in mice was shown to result in multiple metabolic impairments, including increased mitochondrial uncoupling and reduced availability of multiple metabolic proteins (Boudina et al., 2009). Additionally, a novel physical interaction between Insulin Receptor Substrate-1 and SERCA proteins has been established, with decreased association in the diabetic rat heart noted suggesting a possible functional link between the most proximal stages of insulin signalling and ECC (Algenstaedt et al., 1997). However, it is unclear how translationally relevant these findings are to the human disease setting. Cardiac biopsies from human diabetic patients revealed an unexpected increase in activation of IRS-1 and PI3K, suggesting that limitations in GLUT4 trafficking in the diabetic heart may not be a consequence of deficits in insulin signal transduction (Cook et al., 2010).

What is clear is that the diabetic myocardium displays IR and impaired insulin action, and that this is fundamentally linked to reduced PM GLUT4 expression (Cook et al., 2010). Therefore, the third and final proposed mechanism linking impaired metabolism and diastolic dysfunction is reduced GLUT4 mediated glucose uptake, which is critical to cardiac function for several reasons already outlined. This is an intriguing theory as it pinpoints a single protein as having a critical disease modifying role. Interestingly, cardiomyocyte specific knock out of GLUT4 in mice induces a similar phenotype to DCM, with cellular hypertrophy accompanied by an impairment in contractility and relaxation that is linked to altered calcium handling and at least partially explained by a significant reduction in ryanodine receptor and SERCA expression (Domenighetti et al., 2010). Furthermore, ex vivo study of perfused $d b / d b$ mouse hearts revealed characteristic impairments in cardiac contractility and altered substrate utilisation (in favour of FA), all of which was normalised by 4- to 6 -fold transgenic overexpression of GLUT4 (Belke et al., 2000). A follow up study with the same model provided similar findings when utilising in vivo echocardiography and demonstrated normalisation of parameters such as the E/A ratio in $d b / d b$ mice with overexpression of GLUT4 (Semeniuk, Kryski \& Severson, 2002). In further support of this argument, perfusion of isolated $d b / d b$ hearts with a high insulin and high glucose solution increased the efficiency of the diabetic myocardium, and improved recovery post ischemic injury (Hafstad et al., 2007).

Metabolic perturbations are a driving factor in the early pathogenesis of DCM. There is credible evidence citing both increased abundance of FA intermediates and impairments of insulin signalling as important defects, both of which are valuable therapeutic targets. However, considering insight from both human patients and animal models, the major focus of the rest of this review is to consider that restoring cardiac GLUT4-mediated glucose uptake could be of sufficient power to reverse the onset and progression of DCM. This could be a key target for novel therapeutic strategies.

\section{How to develop novel treatment interventions?}

Novel treatment strategies that target the cause of DCM are urgently required. The generally applied framework when developing a therapeutic intervention is to identify biochemical pathways relevant to the pathophysiological event of interest, in order to target key proteins for pharmacological activation / inhibition. This is challenging for DCM, where multiple mechanisms are of relevance at different stages of disease progression.

Peer) reviewing PDF | (2021:01:56957:1:1:NEW 15 Apr 2021) 
338 As outlined, there is strong evidence that impaired insulin stimulated GLUT4 trafficking and

339 therefore glucose uptake are critical early events in DCM, making insulin resistance a priority

340 target. However, numerous factors may contribute towards this, creating a need for multiple

341 points of intervention. For example, pro-inflammatory adipocytokines (IL-6,TNF- $\alpha$ ) from

342 enlarged, inflamed adipose tissue and myocardial accumulation of DAG from increased FA

343 uptake have both been linked to inhibition of proximal insulin signalling intermediates

344 (Plomgaard et al., 2005; Erion \& Shulman, 2010). Additionally, altered SNARE protein

345 expression could indicate disruption of the effector proteins that mechanically regulate GLUT4

346 translocation (Schlaepfer et al., 2003; Lancha et al., 2015). When combined with multiple

347 secondary factors implicated in the pathogenesis of DCM such as advanced glycaemic end-

348 products, reactive oxygen species and local inflammation (Murtaza et al., 2019) it becomes

349 challenging to decide where to begin.

350 Further complications for drug development include a reliance on the animal models that have

351

352

353

354

355

356

357

358

359

360

361

362

363

364

365

366

367

368

369

370

371

372

373

374

375

376

377

378

379 been invaluable in furthering our understanding of cardiac physiology, yet fall short of replicating human disease (Bugger \& Abel, 2014). Therapeutic intervention has also been hampered by the common issue among pharmacological agents under development of unacceptable off target cardiotoxicity.

While there are numerous examples of successful drug development for various diseases, in the specific context of DCM there may be an alternative treatment that could be implemented either alongside, or in place of, conventional pharmacological strategies. Ideally this treatment would be capable of restoring cardiac GLUT4 mediated glucose uptake, whilst also directly positively impacting other identified pathophysiological mechanisms (not just indirectly through effects upon GLUT4). Preferably it would also be suitable for testing directly upon humans in order to speed up the development process and remove any need for animal research. This treatment could potentially be adapted from one of the longest standing, easy to implement, cost-effective interventions at our disposal - exercise.

\section{Exercise - a key tool in the battle against cardiovascular disease and diabetes}

It is well established that physical activity is fundamental to metabolic and cardiovascular health, dating back to the pioneering study of the incidence of heart disease in London bus drivers and conductors (Morris \& Raffle, 1954). Since then, research has continually demonstrated the beneficial effect of exercise upon a range of physiological functions, in both health and disease (see Figure 4) (Thyfault \& Bergouignan, 2020; Pillon et al., 2021).

Overall cardiovascular 'fitness' is often represented by the maximum amount of oxygen an individual can take up and utilise $\left(\mathrm{VO}_{2 \max }\right)$. This is dependent upon the oxygen carrying capacity of the blood, the rate of oxygen diffusion across peripheral and pulmonary capillaries (influenced by capillary density) and the oxygen utilisation capacity of peripheral tissues (mostly skeletal muscle); however, it is primarily representative of cardiac pump capacity (Bassett \& Howley, 2000). The ease of collecting and analysing expired gas samples during a treadmill or stationary bike ramp protocol versus advanced cardiac imaging techniques also makes this parameter relatively accessible for cardiovascular research.

Whilst additional factors, such as running economy and anaerobic threshold, are critical determinants in separating athletes during a race, in a general population $\mathrm{VO}_{2 \max }$ is an excellent 
380 predictor of endurance capacity (Larsen \& Sheel, 2015) and the gold standard for measuring

381

382

383

384

385

386

387

388

389

390

391

392

393

394

395

396

397

398

399

400

401

402

403

404

405

406

407

408

409

410

411

412

413

414

415

416

417

418

419

420

421 aerobic power. $\mathrm{VO}_{2 \max }$ is also a strong predictor of an individual's risk of developing both insulin resistance and cardiovascular disease (Laukkanen et al., 2007; Leite et al., 2009) and also the risk of mortality in heart failure patients (Cohn et al., 1993).

Research has repeatedly demonstrated the capacity of exercise training to improve $\mathrm{VO}_{2 \max }$ in healthy individuals, to the extent that now the effect of relevant variables such as work intensity (Milanović, Sporiš \& Weston, 2015) or session structure (Sindiani et al., 2017) to maximise this benefit are now being investigated. Critically, high intensity exercise has also been shown to effectively increase $\mathrm{VO}_{2 \max }$ in patients with coronary artery disease, heart failure or post-MI (Wisløff et al., 2002, 2007; Moholdt et al., 2012; Liou et al., 2016), demonstrating the therapeutic potential of exercise and the plasticity of the cardiovascular system even when operating at reduced capacity.

The ability of exercise to induce chronic adaptations in cardiac structure and function has also been shown via techniques such as transthoracic echocardiography. The concept of an 'athlete's heart' is well defined; prolonged adherence to exercise training results in hypertrophy of the left ventricular wall (Trachsel et al., 2018). Endurance training may also increase the internal diameter of the left ventricular chamber in response to chronic volume overload (eccentric hypertrophy), whereas more resistance-based training does not (concentric hypertrophy), although few athletes adhere to only one type of training (Fagard, 1992). Whilst hypertrophy is associated with negative outcomes in the context of cardiac disease, with exercise training this is a beneficial adaptive response that aids contractile output and relies upon distinct signalling pathways, in particular activation of IGF-1-receptors and PI3K signalling (Neri Serneri et al., 2001; McMullen et al., 2003). Additionally, imaging of the heart also reveals that exercise has the capacity to greatly enhance cardiac diastolic function, as reflected in the velocity of tissue movement and blood flow, in both healthy individuals and heart failure patients (Levy et al., 1993; Pearson, Mungovan \& Smart, 2017).

Exercise training can also elicit metabolic adaptations, including in tissues other than skeletal muscles (Thyfault \& Bergouignan, 2020). In healthy individuals a key adaptation to endurance training is increased capacity to oxidise fat as a fuel source during acute bouts of exercise, even at workloads of higher intensity (Klein, Coyle \& Wolfe, 1994; Coggan et al., 2000). This preserves limited carbohydrate stores and is attributed to increased skeletal muscle mitochondrial content and therefore capacity (Jacobs et al., 2013; Scalzo et al., 2014). For individuals with either T1D or T2D exercise training is even more impactful. Evidence demonstrates that aerobic, resistance or combined exercise training may improve glycaemic control in diabetic patients, whether measured by blood glucose concentration or circulating $\mathrm{HbA}$ (1c) (Maiorana et al., 2002; Sigal et al., 2007; Tomas-Carus et al., 2016; Röhling et al., 2016), the latter of which has been shown to be an excellent predictor of mortality risk (Khaw et al., 2001). Similar to healthy individuals, this may be in part independent of exercise induced weight loss (Boulé et al., 2001), and instead attributable to improved insulin sensitivity (glucose uptake) and enhanced mitochondrial function (O'Gorman et al., 2006; Meex et al., 2010; Little et al., 2011).

\section{Exercise may also specifically halt the progression of DCM}


422 Short term (typically 12 weeks) exercise-based interventions may enhance impaired diastolic 423 capacity in patients with T2D, with higher intensity exercise typically producing superior results 424 and, in some cases, restoring function to control values (Brassard et al., 2007; Hollekim-Strand

425

426

427

428

429

430

431

432

433

434

435

436

437

438

439

440

441

442

443

444

445

446

447

448

449

450

451

452

453

454

455

456

457

458

459

460

461

462

463

464 et al., 2014; Cugusi et al., 2015; Cassidy et al., 2016). While there are studies where exercise was found to have no beneficial effect (Loimaala et al., 2007), longer-term follow-ups (1 and 3 years) indicated that this may be linked to either poor adherence or insufficient exercise intensity (Hordern et al., 2009; Hare et al., 2011). A recent meta-analysis also concluded that exercise can exert beneficial effects on cardiac diastolic function in diabetic patients (Verboven et al., 2019). The extent of those effects are dependent upon several factors, including the measurement tool and parameters of choice, and the nature of the implemented training.

Exercise has been proposed to elicit beneficial effects through multiple mechanisms, as recently reviewed (Hafstad, Boardman \& Aasum, 2015; Seo et al., 2019) and indicated in Figure 4. The extent to which we can probe human tissue for further insights is limited; however, when focussing on key functional parameters from rodent models, it appears that normalising calcium handling is critical. In $d b / d b$ mice, an interval-based exercise programme returned systolic and diastolic function of the whole heart in vivo and in isolated cardiomyocytes to levels recorded in wild type controls, primarily attributable to normalisation of the calcium transient (Stølen et al., 2009). This in turn was linked to restored sarcoplasmic reticulum calcium loading through enhanced expression and activity of SERCA, and preservation of the t-tubule network. Whilst specific details vary across models or studies, a consistent finding in this field is exercise induced restoration of cardiomyocyte calcium handling dynamics linked to enhanced SERCA activity (Mishra et al., 2011; Epp et al., 2013).

Overall, it is clear that exercise training can enhance diastolic cardiac function in diabetic patients, most likely through a multi-faceted mechanism. There is good evidence that altered substrate utilisation and subsequent mitochondrial dysfunction and limitations in ATP availability are linked to cardiac dysfunction in DCM. Therefore, it is perhaps unsurprising that exercisebased interventions have been shown to enhance mitochondrial biogenesis, structure and function (ATP availability) and restore myocardial glucose utilisation (Figure 4) (Searls et al., 2004; Broderick, Poirier \& Gillis, 2005; Wang et al., 2015). Moreover, exercise-based interventions have had positive effects on cardiac metabolism in humans and rodents (Shao \& Tian, 2015; Gibb \& Hill, 2018). Whilst there is no direct evidence conclusively demonstrating that these adaptations are the primary instigator of improved calcium handling, it is a reasonable theory that should be investigated by future work.

Notably, one study reported that cardiac lipid content was unaltered by an exercise intervention (Schrauwen-Hinderling et al., 2011). This is arguably unsurprising as trained individuals commonly have elevated levels of intramuscular lipids that correlate with high levels of insulin sensitivity (the 'athlete's paradox'). Exercise may alleviate lipotoxicity through a reduction in toxic lipid intermediates (e.g. ceramide), improved mitochondrial efficiency and increased lipid turnover, as opposed to simply reducing total cellular lipid content. This underscores the multifaceted impact of exercise training upon metabolic function.

\section{Can we specifically target GLUT4 with exercise?}

The fundamental principle of exercise training is that if we impose specific demands upon a physiological system then with subsequent rest and recovery a specific adaptation process will

Peer] reviewing PDF | (2021:01:56957:1:1:NEW 15 Apr 2021) 
465

466

467

468

469

470

471

472

473

474

475

476

477

478

479

480

481

482

483

484

485

486

487

488

489

490

491

492

493

494

495

496

497

498

499

500

501

502

503

504

505

506

507

occur that will enhance performance in response to future stress. Despite this, the use of generic strength and / or endurance exercise interventions in scientific research is widespread. There are sound experimental reasons for this approach e.g. to standardise workloads across subjects, yet the limitations are rarely acknowledged. Exercise is often referred to and discussed as a singular entity, rather than as an adaptable process allowing a diverse range of stimuli to be implemented. Therefore, prior work investigating the impact of exercise on DCM may have barely scratched the surface of what can be achieved. Previous studies with one standardised intervention, often with limited overall loading, are likely to have produced suboptimal improvements.

In theory it should be possible to design an exercise-based intervention that specifically targets maximal upregulation of insulin-stimulated GLUT4 mediated glucose uptake in patients with DCM (Figure 4). Rather than relying on the generally beneficial effects of exercise, training would be tailored to target alleviation of cardiac insulin resistance - one of the fundamental events in the early pathogenesis of DCM. In this regard it may be useful to consider strategies known to enhance GLUT4 expression in skeletal muscle (Richter \& Hargreaves, 2013), as similar regulatory networks may also operate in heart tissue.

Prior work with healthy rats demonstrates that exercise regimes can increase cardiac GLUT4 protein expression (Palabiyik et al., 2016; Schaun et al., 2017). Endurance running training has also been found to prevent large diabetes-induced decreases in rat myocardial GLUT4 expression, demonstrating therapeutic potential (Hall, Sexton \& Stanley, 1995; Osborn et al., 1997). Recent studies have also revealed exercise-induced beneficial effects on cardiac metabolism (Gibb \& Hill, 2018) and in human muscle (Wojtaszewski et al., 2000; Richter \& Hargreaves, 2013; Richter, 2020) and parallel changes in skeletal muscle and cardiac GLUT4 levels in response to changes in plasma free fatty acid levels (Murray et al., 2004). Collectively, this work supports the notion that exercise can impact GLUT4 in the diabetic heart but provides no information regarding optimal conditions for human patients.

Separately, multiple studies have demonstrated the capacity of exercise interventions (of varying design and duration) to induce increases in skeletal muscle and adipose tissue GLUT4 protein expression in human diabetics, alongside improved glycaemic control (Dela et al., 1994; Holten et al., 2004; O'Gorman et al., 2006; Hussey et al., 2011; Little et al., 2011). Comparison of trained and sedentary individuals has positively correlated increased insulin mediated phosphorylation of PI3K and glucose uptake in athletes (Kirwan et al., 2000); however, evidence from the obese Zucker rat diabetic model indicates that an increase in GLUT4 protein expression is the primary mechanism that can drive alleviation of skeletal muscle insulin resistance (Etgen et al., 1997; Ivy, 2004). Furthermore, in one study exercise increased whole body insulin mediated glucose disposal despite unchanged activation of key proximal insulin signalling intermediates in skeletal muscle (O'Gorman et al., 2006). This further supports the notion that increasing GLUT4 protein expression in the heart should be the primary target of interventions to alleviate cardiac insulin resistance in the context of DCM.

Exercise enhances GLUT4 expression across all major insulin target tissues. This alone may be sufficient to alleviate tissue specific insulin resistance, as suggested by prior work overexpressing GLUT4 in diabetic mouse models (Belke et al., 2000; Semeniuk, Kryski \& Severson, 2002). Moving forwards, the most beneficial stimulus to induce the desired 
508

509

510

511

512

513

514

515

516

517

518

519

520

521

522

523

524

525

526

527

528

529

530

531

532

533

534

535

536

537

538

539

540

541

542

543

544

545

546

547

548

549

550

adaptations should be identified. Arguably most importantly, the optimal work intensity should be determined. It could be that high intensity interval training (HIIT) is key in order to achieve the maximal rate of glucose uptake possible, or alternatively that steady state endurance training is preferable in order to maximise the total amount of glucose taken up over the whole exercise session. Interestingly, HIIT has previously been found to be most effective at improving diastolic function in diabetic individuals and also aerobic fitness in other cardiac rehabilitation settings (Hollekim-Strand et al., 2014; Cassidy et al., 2016; Hannan et al., 2018). Similarly, the most effective exercise modality and frequency must be identified. Finally, the programming most appropriate to different stages of disease progression should be established, as clinical manifestation can vary from asymptomatic (early stage) to severe debilitation (late stage).

The optimal conditions would be easier to identify if the mechanisms regulating GLUT4 expression were better understood. Numerous transcription factors have been cited as having a regulatory role over GLUT4 gene transcription, with particular emphasis on MyoD, MEF2 and the Thyroid hormone receptor (Zorzano, Palacín \& Gumà, 2005). Accordingly, increased nuclear localisation and DNA binding of MEF2 has been identified in the skeletal muscle of human subjects after an acute exercise bout (McGee et al., 2006). Moving forwards, a comprehensive list of regulatory factors must be detailed, before assessing the impact of key exercise variables upon their activity. Additionally, increased skeletal muscle GLUT4 protein content independent of chronic changes in GLUT4 mRNA were noted in response to a 4-week running programme in high-fat fed mice, suggesting that regulation of the expression of GLUT4 may not be limited to transcriptional mechanisms (Gurley, Griesel \& Olson, 2016).

\section{Side effects and limitations of exercise}

The aim of this review is not to argue that exercise programmes should replace all pharmacological strategies in the management of DCM. Rather, we seek to highlight the underappreciated and under investigated potential of exercise to act as a first point of intervention. A further benefit of appropriately managed exercise training is that unlike many drugs there is a lack of off target adverse side effects.

Media reporting of exercise-induced sudden cardiac death (particularly in mass-participation sports) can elevate the perceived risk; however, in reality it is rare. Estimates place the risk at between 1:40,000 to 1:80,000, with the majority of cases linked to previously undiscovered cardiomyopathy (de Noronha et al., 2009; Harmon et al., 2014). A 'J-shaped' relationship between exercise duration and risk of sudden cardiac death has been described previously; however, any elevation in risk may not be observed until weekly exercise duration exceeds 10 hours, which is unlikely to apply to training designed for individuals with DCM. Additionally, evidence linking long term regular strenuous exercise with potentially adverse cardiac remodelling (fibrosis; coronary artery calcification) does not stand up against the clear reduction in major cardiovascular events and mortality observed in moderately and highly physically active individuals (Eijsvogels et al., 2016).

Given the nature of DCM, it is logical to suggest that there could be an elevated risk in this patient population. However, a meta-analysis of randomised control trials including data from over 6,000 post-MI patients demonstrated exercise-based interventions significantly reduced their risk of reinfarction and all-cause mortality (Lawler, Filion \& Eisenberg, 2011). Similarly, a meta-analysis of heart failure patients demonstrated a reduced rate of rehospitalisation and

PeerJ reviewing PDF | (2021:01:56957:1:1:NEW 15 Apr 2021) 
551 improved quality of life in response to exercise rehabilitation (Taylor et al., 2019). Importantly, a

552

553

554

555

556

557

558

559

560

561

562

563

564

565

566

567

568

569

570

571

572

573

574

575

576

577

578

579

580

581

582

583

584

585

586

587

588

589

590

591

592

593 study of 4,846 coronary heart disease patients undergoing exercise-based rehabilitation demonstrated extremely low rates of exercise induced sudden cardiac death, even during sessions of higher intensity (Rognmo et al., 2012). Overall, this suggests that properly designed exercise programmes for patients undergoing rehabilitation from various cardiac diseases are safe, and that the benefits accrued greatly outweigh any associated risk.

The biggest limitation of exercise-based interventions is undoubtedly adherence. Understanding reasons for non-completion and how to overcome psychological barriers to adherence are key areas of research (Bock et al., 1997; Aamot et al., 2016). This could mean adapting prescribed workouts to meet individual needs and preferences. Consideration of this should be central to the design of any intervention, as adopting a holistic approach will provide the greatest chance of success. Perhaps this is an early-stage version of personalised medicine!

If properly implemented, any side effects associated with exercise training are more likely to be positive. As stated, one of the key benefits of exercise is that it has the capacity to improve multiple aspects of physiological function. Therefore, even if designing an intervention to enhance cardiac glucose uptake, it is likely that other aspects of patient health would improve. For example, regular exercise combined with caloric restriction will likely result in clinically significant ( $>5 \%$ ) weight loss (Swift et al., 2018). Obesity is not only a major risk factor for diabetes, but also for multiple other conditions such as coronary heart disease (Abbasi et al., 2002). These benefits can be accrued at nominal cost, therefore allowing healthcare resources to be focussed where they are needed most. The recently described remission of T2D by dietary modification provides a clear illustration of this (Taylor, 2019), and the impact of this on cardiac function is eagerly awaited. Finally, exercise has been recognised as a powerful tool to alleviate the symptoms of anxiety and depression (Carek, Laibstain \& Carek, 2011; Jones et al., 2016). This means that exercise-based interventions could enhance the psychological wellbeing of DCM patients through both direct and indirect mechanisms.

\section{One size may not fit all.}

Increased aerobic exercise capacity is a key health-promoting benefit of regular aerobic exercise, but humans vary considerably in their ability to respond to exercise. The 'exercise capacity' phenotype has been increasingly recognised as a predictor of health and longevity (Grundy et al., 2012; Kokkinos et al., 2014), raising the interesting question of what might limit the capacity of individuals to respond - might there be environmental or genetics factors at work?

Building on evidence that has linked low exercise capacity and hyperglycaemia, MacDonald et al evaluated whether chronic hyperglycaemia - specifically consumption of a 'western diet' or the induction of experimental diabetes - impacted exercise-induced improvements in aerobic capacity and skeletal muscle remodelling in rodents. This study revealed that exercise-induced improvements in aerobic capacity and associated skeletal muscle remodelling were impaired in models associated with chronic hyperglycemia (MacDonald et al., 2020). This ground-breaking study further identified a signalling network that is aberrantly activated by aerobic exercise in rodents with hyperglycaemia (and also humans). This involved both glucose-mediated modifications of the extracellular matrix and altered JNK-signalling in muscle (MacDonald et al., 2020).

PeerJ reviewing PDF | (2021:01:56957:1:1:NEW 15 Apr 2021) 
594 Somewhat surprisingly, mice with hyperglycaemia exhibited elevated GLUT4 muscle levels and

595

596

597

598

599

600

601

602

603

604

605

606

607

608

609

610

611

612

613

614

615

616

617

618

619

620

621

622

623

624

625

626

627

628

629

630

631

632

633

634

635 improved glucose tolerance with training. As noted by MacDonald, this hints that 'metabolic improvements with exercise are dissociated from improvements in exercise capacity' (MacDonald et al., 2020), which raises the possibility that exercise-induced improvements in glucose metabolism might reduce the burden of low improvements in aerobic capacity. Future work in this area will be of great interest. The increasing incidence of hyperglycaemia may therefore be acting in as yet unappreciated ways to impair metabolic health. Whether such adaptations also underpin cardiac muscle function remain unexplored.

Finally, a recent study from Abel and colleagues noted that that restoring glucose delivery to cardiomyocytes in the context of streptozotocin-induced diabetes could result in acceleration of mitochondrial dysfunction, an effect mediated by elevated O-GIcNAcylation of the transcription factor Sp1 (Wende et al., 2020). They argue this work supports previous studies indicating that myocardial insulin resistance (i.e. decreased glucose uptake) may be cardioprotective (Taegtmeyer et al., 2013) and posit that the reduced glucose utilisation observed in diabetic cardiomyopathy may act as a defence mechanism against glucotoxicity. This latter point needs to be investigated directly, as data from streptozotocin-induced diabetes may not correlate with DCM. It is well established that GLUT4 is the major contributor to glucose uptake in the beating heart and that GLUT4 levels are reduced in DCM, prompting Wende et al assert that 'increasing or maintaining GLUT4 expression in the heart represents a reasonable approach for preserving myocardial glucose utilisation in the context of diabetes' (Wende et al., 2020).

\section{Could iPSC-CM help in this field?}

Human induced pluripotent stem-cell derived cardiomyocytes (iPSC-CM) are a relatively recently developed technology that have potential applications in the study of cardiac development and disease or in the practical fields of drug toxicity screening and even cardiac regeneration (Del Álamo et al., 2016; Shiba et al., 2016). iPSC-CM are presently considered to represent cardiomyocytes at a foetal stage of development. Whilst they express many cardiac specific genes and proteins and exhibit contractile activity, their structure (lacking t-tubules, poorly organised myofilaments), metabolism (dependence upon glucose) and electrophysiological profile (elevated resting diastolic potential, slow action potential upstroke velocity) require development in order to achieve the level of comparative physiology required for optimal application (Correia et al., 2017; Parikh et al., 2017).

Previously, features consistent with pathological hypertrophy and altered calcium handling were induced in iPSC-CM through exposure to elevated levels of endothelin-1 and cortisol (Drawnel et al., 2014). This was taken as evidence of having developed a physiologically relevant model of DCM. However, a notable limitation of this paper was the absence of any reference to insulin stimulated glucose uptake or related metabolic parameters. To date, only 2 publications have claimed to have induced an insulin resistant phenotype in iPSC-CM, through culturing cells in the presence of elevated levels of palmitate or TNF-alpha and recording reduced insulin stimulated glucose uptake and reduced phosphorylation of Akt (Liu et al., 2017; Chanda et al., 2017). This data is promising; however, it must be noted that at baseline in these studies insulin stimulation increased glucose uptake 1.2-1.5 fold, and in both cases the raw unadjusted data was not presented. This makes these results more difficult to interpret, and may not compare

PeerJ reviewing PDF | (2021:01:56957:1:1:NEW 15 Apr 2021) 
636 favourably to data from isolated primary cardiomyocytes (Fischer et al., 1997; Mazumder et al., 637 2004); but see also (Bryant \& Gould, 2020).

638 We investigated the impact of different experimental conditions upon glucose uptake and insulin 639 sensitivity in commercial iPSC-CM (Bowman, Smith \& Gould, 2019). Through direct comparison

640 to the highly insulin sensitive murine 3T3-L1 adipocyte cell line and isolated adult

641 cardiomyocytes, it was concluded that under appropriate experimental conditions iPSC-CM do

642 not adequately respond to insulin with regards to their rate of glucose uptake. We have

643 pinpointed very little to no expression of GLUT4 protein as a primary (but not necessarily 644 exclusive) limitation in iPSC-CM in this context (Bowman, Smith \& Gould, 2019). In contrast, 645 these cells express an abundance of GLUT1 protein (Bowman, Smith \& Gould, 2019). This

646 expression profile is consistent with immature foetal cardiomyocytes (Castelló et al., 1994) and

647 represents another parameter that must be altered in order to advance the maturation status of 648 these cells. It will be interesting to ascertain whether the GLUT1/GLUT4 ratio more closely 649 replicates the adult phenotype in more complex systems, such as cardiac organoids (Mills et al., 650 2019) or from iPSC-CMs derived using more complex differentiation systems (Parikh et al., 651 2017; Ronaldson-Bouchard et al., 2018) or grown on different matrices.

652 The lack of GLUT4 protein and insulin stimulated glucose uptake in this cell type prevents 653 generation of a robust model of DCM with iPSC-CM at this time. However, it does provide a 654 unique opportunity to probe the regulation of cardiac GLUT4 protein expression (and 655 subsequent trafficking) by exercise training. iPSC-CM spontaneously beat in culture; however, 656 their contractile activity can also be regulated through external field-based stimulation or 657 optogenetic control (Lapp et al., 2017). These techniques could facilitate conditioning protocols 658 that provide a stimulus analogous to exercise training. Through varying the frequency, duration, 659 and intensity of this stimulus and observing the effects upon GLUT4 protein expression we 660 could obtain valuable information that can inform optimal strategies for subsequent programmes 661 in humans.

662

\section{Conclusions}

664 Diabetic cardiomyopathy develops from initial metabolic alterations and leads to progressive 665 functional and structural adaptations that can ultimately result in heart failure. Impaired 666 regulation of the subcellular distribution of GLUT4 has emerged as an important early 667 pathological event. Exercise can counteract a range of pathophysiological mechanisms and 668 consequences of diabetes, and suitable programmes could and therefore should be developed 669 to specifically target GLUT4 alongside current pharmacological strategies. The rapidly

670 developing iPSC-CM technology could be of benefit in this field.

671

\section{Acknowledgements}

673 We are most grateful to Tomas Stølen (Norwegian University of Science and Technology and

674 Trondheim University Hospital) for helpful and insightful comments on the manuscript.

675

Conflict of Interests: none declared. 
677 Figure legends.

678 Figure $1 \quad$ Mechanisms of diabetic cardiomyopathy

679 A range of contributory factors in the development of diabetic cardiomyopathy have been

680 proposed. These include lipotoxicity, impaired insulin signalling, accumulation of advanced

681 glycation end products, ER and oxidative stress. We focus on metabolic disturbance,

682 specifically defects in the GLUT4 glucose transport system.

683

684 Figure 2 Trafficking of GLUT4 and CD36 in cardiomyocytes

685 In the well-perfused healthy heart $>95 \%$ of ATP is produced by oxidative phosphorylation and $68660-90 \%$ of this is derived from metabolism of fatty acids which is the predominantly available 687 substrate. The extraordinary high energetic demand of the heart is underpinned by an ability to 688 adjust substrate preference to match the energetic demand with the levels of prevailing 689 substrate in the circulation. The ability to 'shift' substrate preference is beneficial (Ritterhoff \& 690 Tian, 2017). For both fatty acids and glucose, flux analysis supports the contention that it is the

691

692 delivery across the plasma membrane (PM) that controls the flux through the respective metabolic pathways. CD36 is a multifunctional protein which mediates $\sim 70 \%$ of the uptake of

693 fatty acids in cardiomyocytes. GLUT4 is the predominant glucose transporter in cardiomyocytes

694

695 (Abel, 2004; Luiken et al., 2020). Both recycle between intracellular stores and the PM. In response to insulin or contraction, PM levels of CD36 and GLUT4 increase. [Note that different

696

697 populations of intracellular GLUT4 are mobilised by insulin or contraction, but this is not shown here for simplicity]. Once inside the cell, fatty acids are rapidly converted into fatty acyl CoA by

698 fatty acyl CoA synthase which are then substrates for $\beta$-oxidation in mitochondria. Similarly, glucose is rapidly converted to glucose-6-phosphate and metabolised to pyruvate in the cytosol and then enters the TCA cycle. Reduced expression of the mitochondrial pyruvate carrier proteins is associated with cardiac hypertrophy in human heart (Fernandez-Caggiano et al., 2020). Hence, cardiomyocyte metabolism is considered to be highly adaptive and tightly

703 regulated by hormonal and contraction signals, coupling fuel use with available substrate and

704 metabolic need.

705

\section{Figure 3 Possible metabolic abnormalities leading to diastolic dysfunction}

Three possible mechanisms are discussed which may link impaired cardiomyocyte energy metabolism to diastolic dysfunction. These include changes in the balance of fuel use.

709 Increased fatty acid transport and fatty acid cytosolic levels are associated with over-feeding and may lead to insulin resistance and starve the heart of the glucose that it needs to rapidly and efficiently generate the ATP that powers excitation contraction coupling. A high fat diet is known to increase cell surface CD36 levels and reduce levels of GLUT4 at the PM, giving rise to increased fatty acid metabolism and the accumulation of toxic lipid metabolites such as ceramide [1]. Impaired insulin signalling has also been posited as underlying diabetic cardiomyopathy [2]; ceramide is also known to inhibit insulin signalling pathways (see text).

716 Although a relatively small contributor to total cardiac metabolism in the healthy heart (Ingwall, 717 2009; Ritterhoff \& Tian, 2017), in this review, we focus on reduced glucose uptake and 
718 decreased levels of GLUT4 [3] as a key underpinning mechanism in diabetic cardiomyopathy

719 and consider whether restoration of GLUT4 levels may be a useful therapeutic intervention.

720 Figure $4 \quad$ Key mechanisms through which exercise may improve cardiac function in

721 DCM.

722 Shown are several mechanisms through which exercise training may alleviate cardiac

723 dysfunction associated with DCM. Firstly, exercise may normalise cardiac metabolism, which could directly enhance cardiac contractile function through increasing ATP availability. Similarly, exercise has been shown to alleviate impairments in cardiomyocyte calcium handling, which could directly enhance contractile function through more efficient use of ATP. It is unclear if these adaptive mechanisms occur independently or if there is a functional link. Finally, general global benefits of exercise training such as weight loss could reduce the burden on the diabetic heart, thus improving function. Please note that we have limited our discussion to what we consider to be key potential mechanisms; see main text for further details. 
732

733

734

735

736

737

738

739

740

741

742

743

744

745

746

747

748

749

750

751

752

753

754

755

756

757

758

759

760

761

762

763

764

765

766

767

768

769

770

771

772

773

774

775

776

777

\section{Bibliography}

Aamot I-L., Karlsen T., Dalen H., Støylen A. 2016. Long-term Exercise Adherence After Highintensity Interval Training in Cardiac Rehabilitation: A Randomized Study. Physiotherapy Research International 21:54-64.

Abbasi F., Brown BW., Lamendola C., McLaughlin T., Reaven GM. 2002. Relationship between obesity, insulin resistance, and coronary heart disease risk. Journal of the American College of Cardiology 40:937-943.

Abdurrachim D., Prompers JJ. 2018. Evaluation of cardiac energetics by non-invasive 31P magnetic resonance spectroscopy. Biochimica et biophysica acta. Molecular basis of disease 1864:1939-1948.

Abel ED. 2004. Glucose transport in the heart. Frontiers in Bioscience 9:201-215.

Abel ED. 2018. Mitochondrial dynamics and metabolic regulation in cardiac and skeletal muscle. Transactions of the American Clinical and Climatological Association 129:266278.

Adams JM., Pratipanawatr T., Berria R., Wang E., DeFronzo RA., Sullards MC., Mandarino LJ. 2004. Ceramide content is increased in skeletal muscle from obese insulin-resistant humans. Diabetes 53:25-31.

Algenstaedt P., Antonetti DA., Yaffe MB., Kahn CR. 1997. Insulin receptor substrate proteins create a link between the tyrosine phosphorylation cascade and the Ca2+-ATPases in muscle and heart. The Journal of Biological Chemistry 272:23696-23702.

Arikawa E., Ma RCW., Isshiki K., Luptak I., He Z., Yasuda Y., Maeno Y., Patti ME., Weir GC., Harris RA., Zammit VA, Tian R., King GL. 2007. Effects of insulin replacements, inhibitors of angiotensin, and PKCbeta's actions to normalize cardiac gene expression and fuel metabolism in diabetic rats. Diabetes 56:1410-1420.

Atkinson BJ., Griesel BA., King CD., Josey MA., Olson AL. 2013. Moderate GLUT4 overexpression improves insulin sensitivity and fasting triglyceridemia in high-fat dietfed transgenic mice. Diabetes 62:2249-2258.

Bashir A., Coggan AR., Gropler RJ. 2015. In vivo creatine kinase reaction kinetics at rest and stress in type II diabetic rat heart. Physiological reports 3.

Bassett DR., Howley ET. 2000. Limiting factors for maximum oxygen uptake and determinants of endurance performance. Medicine and Science in Sports and Exercise 32:70-84.

Belke DD., Dillmann WH. 2004. Altered cardiac calcium handling in diabetes. Current Hypertension Reports 6:424-429.

Belke DD., Larsen TS., Gibbs EM., Severson DL. 2000. Altered metabolism causes cardiac dysfunction in perfused hearts from diabetic $(\mathrm{db} / \mathrm{db})$ mice. American Journal of Physiology. Endocrinology and Metabolism 279:E1104-13.

Bell DSH. 2003. Heart failure: the frequent, forgotten, and often fatal complication of diabetes. Diabetes Care 26:2433-2441.

Bers DM. 2002. Cardiac excitation-contraction coupling. Nature 415:198-205.

von Bibra H., Diamant M., Scheffer PG., Siegmund T., Schumm-Draeger P-M. 2008. Rosiglitazone, but not glimepiride, improves myocardial diastolic function in association with reduction in oxidative stress in type 2 diabetic patients without overt heart disease. Diabetes \& vascular disease research : official journal of the International Society of Diabetes and Vascular Disease 5:310-318.

Bock BC., Albrecht AE., Traficante RM., Clark MM., Pinto BM., Tilkemeier P., Marcus BH. 
778

779

780

781

782

783

784

785

786

787

788

789

790

791

792

793

794

795

796

797

798

799

800

801

802

803

804

805

806

807

808

809

810

811

812

813

814

815

816

817

818

819

820

821

822

823

1997. Predictors of exercise adherence following participation in a cardiac rehabilitation program. International Journal of Behavioral Medicine 4:60-75.

Boudina S., Bugger H., Sena S., O’Neill BT., Zaha VG., Ilkun O., Wright JJ., Mazumder PK., Palfreyman E., Tidwell TJ., Theobald, H, Khalimonchuk, O., wayment B., Sheng X., Rodnick, KJ, Centini, R., Chen D., Liwin SE., Weimer BE, Abel ED. 2009. Contribution of impaired myocardial insulin signaling to mitochondrial dysfunction and oxidative stress in the heart. Circulation 119:1272-1283.

Boudina S., Han YH., Pei S., Tidwell TJ., Henrie B., Tuinei J., Olsen C., Sena S., Abel ED. 2012. UCP3 regulates cardiac efficiency and mitochondrial coupling in high fat-fed mice but not in leptin-deficient mice. Diabetes 61:3260-3269.

Boudina S., Sena S., Theobald H., Sheng X., Wright JJ., Hu XX., Aziz S., Johnson JI., Bugger H., Zaha VG., Abel ED. 2007. Mitochondrial energetics in the heart in obesity-related diabetes: direct evidence for increased uncoupled respiration and activation of uncoupling proteins. Diabetes 56:2457-2466.

Boulé NG., Haddad E., Kenny GP., Wells GA., Sigal RJ. 2001. Effects of exercise on glycemic control and body mass in type 2 diabetes mellitus: a meta-analysis of controlled clinical trials. The Journal of the American Medical Association 286:1218-1227.

Bowman PRT., Smith GL., Gould GW. 2019. GLUT4 expression and glucose transport in human induced pluripotent stem cell-derived cardiomyocytes. Plos One 14:e0217885.

Boyer JK., Thanigaraj S., Schechtman KB., Pérez JE. 2004. Prevalence of ventricular diastolic dysfunction in asymptomatic, normotensive patients with diabetes mellitus. The American Journal of Cardiology 93:870-875.

Brassard P., Legault S., Garneau C., Bogaty P., Dumesnil J-G., Poirier P. 2007. Normalization of diastolic dysfunction in type 2 diabetics after exercise training. Medicine and Science in Sports and Exercise 39:1896-1901.

Broderick TL., Poirier P., Gillis M. 2005. Exercise training restores abnormal myocardial glucose utilization and cardiac function in diabetes. Diabetes/Metabolism Research and Reviews 21:44-50.

Brown NF., Weis BC., Husti JE., Foster DW., McGarry JD. 1995. Mitochondrial carnitine palmitoyltransferase I isoform switching in the developing rat heart. The Journal of Biological Chemistry 270:8952-8957.

Bryant NJ., Gould GW. 2020. Insulin stimulated GLUT4 translocation - Size is not everything! Current Opinion in Cell Biology 65:28-34.

Bugger H., Abel ED. 2014. Molecular mechanisms of diabetic cardiomyopathy. Diabetologia 57:660-671.

Cao F., Maguire ML., McAndrew DJ., Lake HA., Neubauer S., Zervou S., Schneider JE., Lygate CA. 2020. Overexpression of mitochondrial creatine kinase preserves cardiac energetics without ameliorating murine chronic heart failure. Basic Research in Cardiology 115:12.

Carek PJ., Laibstain SE., Carek SM. 2011. Exercise for the treatment of depression and anxiety. International Journal of Psychiatry in Medicine 41:15-28.

Cassidy S., Thoma C., Hallsworth K., Parikh J., Hollingsworth KG., Taylor R., Jakovljevic DG., Trenell MI. 2016. High intensity intermittent exercise improves cardiac structure and function and reduces liver fat in patients with type 2 diabetes: a randomised controlled trial. Diabetologia 59:56-66.

Castelló A., Rodríguez-Manzaneque JC., Camps M., Pérez-Castillo A., Testar X., Palacín M., Santos A., Zorzano A. 1994. Perinatal hypothyroidism impairs the normal transition of 
824

825

826

827

828

829

830

831

832

833

834

835

836

837

838

839

840

841

842

843

844

845

846

847

848

849

850

851

852

853

854

855

856

857

858

859

860

861

862

863

864

865

866

867

868

869

GLUT4 and GLUT1 glucose transporters from fetal to neonatal levels in heart and brown adipose tissue. Evidence for tissue-specific regulation of GLUT4 expression by thyroid hormone. The Journal of Biological Chemistry 269:5905-5912.

Chanda D., Oligschlaeger Y., Geraets I., Liu Y., Zhu X., Li J., Nabben M., Coumans W., Luiken JJFP., Glatz JFC., Neumann D. 2017. 2-Arachidonoylglycerol ameliorates inflammatory stress-induced insulin resistance in cardiomyocytes. The Journal of Biological Chemistry 292:7105-7114.

Ciaraldi TP., Mudaliar S., Barzin A., Macievic JA., Edelman SV., Park KS., Henry RR. 2005. Skeletal muscle GLUT1 transporter protein expression and basal leg glucose uptake are reduced in type 2 diabetes. The Journal of Clinical Endocrinology and Metabolism 90:352-358.

Coggan AR., Raguso CA., Gastaldelli A., Sidossis LS., Yeckel CW. 2000. Fat metabolism during high-intensity exercise in endurance-trained and untrained men. Metabolism: Clinical and Experimental 49:122-128.

Cohn JN., Johnson GR., Shabetai R., Loeb H., Tristani F., Rector T., Smith R., Fletcher R. 1993. Ejection fraction, peak exercise oxygen consumption, cardiothoracic ratio, ventricular arrhythmias, and plasma norepinephrine as determinants of prognosis in heart failure. The V-HeFT VA Cooperative Studies Group. Circulation 87:VI5-16.

Cole MA., Murray AJ., Cochlin LE., Heather LC., McAleese S., Knight NS., Sutton E., Jamil AA., Parassol N., Clarke K. 2011. A high fat diet increases mitochondrial fatty acid oxidation and uncoupling to decrease efficiency in rat heart. Basic Research in Cardiology 106:447-457.

Cook SA., Varela-Carver A., Mongillo M., Kleinert C., Khan MT., Leccisotti L., Strickland N., Matsui T., Das S., Rosenzweig A., Punjabi P, Camici PG. 2010. Abnormal myocardial insulin signalling in type 2 diabetes and left-ventricular dysfunction. European Heart Journal 31:100-111.

Coort SLM., Hasselbaink DM., Koonen DPY., Willems J., Coumans WA., Chabowski A., van der Vusse GJ., Bonen A., Glatz JFC., Luiken JJFP. 2004. Enhanced sarcolemmal FAT/CD36 content and triacylglycerol storage in cardiac myocytes from obese zucker rats. Diabetes 53:1655-1663.

Correia C., Koshkin A., Duarte P., Hu D., Teixeira A., Domian I., Serra M., Alves PM. 2017. Distinct carbon sources affect structural and functional maturation of cardiomyocytes derived from human pluripotent stem cells. Scientific Reports 7:8590.

Cugusi L., Cadeddu C., Nocco S., Orrù F., Bandino S., Deidda M., Caria A., Bassareo PP., Piras A., Cabras S., Mercuro G. 2015. Effects of an aquatic-based exercise program to improve cardiometabolic profile, quality of life, and physical activity levels in men with type 2 diabetes mellitus. $P M \& R$ : the journal of injury, function, and rehabilitation 7:141-8; quiz 148.

Dal Canto E., Ceriello A., Rydén L., Ferrini M., Hansen TB., Schnell O., Standl E., Beulens JW. 2019. Diabetes as a cardiovascular risk factor: An overview of global trends of macro and micro vascular complications. European journal of preventive cardiology 26:25-32.

Daniels L., Bell JR., Delbridge LMD., McDonald FJ., Lamberts RR., Erickson JR. 2015. The role of CaMKII in diabetic heart dysfunction. Heart failure reviews 20:589-600.

Darrabie MD., Arciniegas AJL., Mishra R., Bowles DE., Jacobs DO., Santacruz L. 2011. AMPK and substrate availability regulate creatine transport in cultured cardiomyocytes. American Journal of Physiology. Endocrinology and Metabolism 300:E870-6. 
870 Del Álamo JC., Lemons D., Serrano R., Savchenko A., Cerignoli F., Bodmer R., Mercola M.

871

872

873

874

875

876

877

878

879

880

881

882

883

884

885

886

887

888

889

890

891

892

893

894

895

896

897

898

899

900

901

902

903

904

905

906

907

908

909

910

911

912

913

914

915 2016. High throughput physiological screening of iPSC-derived cardiomyocytes for drug development. Biochimica et Biophysica Acta 1863:1717-1727.

Dela F., Ploug T., Handberg A., Petersen LN., Larsen JJ., Mikines KJ., Galbo H. 1994. Physical training increases muscle GLUT4 protein and mRNA in patients with NIDDM. Diabetes 43:862-865.

Deng J-Y., Huang J-P., Lu L-S., Hung L-M. 2007. Impairment of cardiac insulin signaling and myocardial contractile performance in high-cholesterol/fructose-fed rats. American Journal of Physiology. Heart and Circulatory Physiology 293:H978-87.

Di Bonito P., Cuomo S., Moio N., Sibilio G., Sabatini D., Quattrin S., Capaldo B. 1996. Diastolic dysfunction in patients with non-insulin-dependent diabetes mellitus of short duration. Diabetic Medicine 13:321-324.

Diamant M., Lamb HJ., Groeneveld Y., Endert EL., Smit JWA., Bax JJ., Romijn JA., de Roos A., Radder JK. 2003. Diastolic dysfunction is associated with altered myocardial metabolism in asymptomatic normotensive patients with well-controlled type 2 diabetes mellitus. Journal of the American College of Cardiology 42:328-335.

Doenst T., Nguyen TD., Abel ED. 2013. Cardiac metabolism in heart failure: implications beyond ATP production. Circulation Research 113:709-724.

Domenighetti AA., Danes VR., Curl CL., Favaloro JM., Proietto J., Delbridge LMD. 2010. Targeted GLUT-4 deficiency in the heart induces cardiomyocyte hypertrophy and impaired contractility linked with $\mathrm{Ca}(2+)$ and proton flux dysregulation. Journal of Molecular and Cellular Cardiology 48:663-672.

Drawnel FM., Boccardo S., Prummer M., Delobel F., Graff A., Weber M., Gérard R., Badi L., Kam-Thong T., Bu L., Jiang X., Hoflack, J-C., Kiialainen A., Jeworutzki E., Aoyama N., Carlson C., Burcon M., Gromo G., Boehringer M., Stahlberg H., Hall BJ., Magnone MC., Kolaja K., Chien KR., Bailly J., Iacone R. 2014. Disease modeling and phenotypic drug screening for diabetic cardiomyopathy using human induced pluripotent stem cells. Cell reports 9:810-821.

D’Souza K., Nzirorera C., Kienesberger PC. 2016. Lipid metabolism and signaling in cardiac lipotoxicity. Biochimica et Biophysica Acta 1861:1513-1524.

Dutka DP., Pitt M., Pagano D., Mongillo M., Gathercole D., Bonser RS., Camici PG. 2006. Myocardial glucose transport and utilization in patients with type 2 diabetes mellitus, left ventricular dysfunction, and coronary artery disease. Journal of the American College of Cardiology 48:2225-2231.

Eijsvogels TMH., Molossi S., Lee D-C., Emery MS., Thompson PD. 2016. Exercise at the extremes: the amount of exercise to reduce cardiovascular events. Journal of the American College of Cardiology 67:316-329.

Elliott AC., Smith GL., Allen DG. 1994. The metabolic consequences of an increase in the frequency of stimulation in isolated ferret hearts. The Journal of Physiology 474:147159.

Epp RA., Susser SE., Morissette MP., Kehler DS., Jassal DS., Duhamel TA. 2013. Exercise training prevents the development of cardiac dysfunction in the low-dose streptozotocin diabetic rats fed a high-fat diet. Canadian Journal of Physiology and Pharmacology 91:80-89.

Erion DM., Shulman GI. 2010. Diacylglycerol-mediated insulin resistance. Nature Medicine $16: 400-402$. 
916 Etgen GJ., Jensen J., Wilson CM., Hunt DG., Cushman SW., Ivy JL. 1997. Exercise training

917

918

919

920

921

922

923

924

925

926

927

928

929

930

931

932

933

934

935

936

937

938

939

940

941

942

943

944

945

946

947

948

949

950

951

952

953

954

955

956

957

958

959

960

961 reverses insulin resistance in muscle by enhanced recruitment of GLUT-4 to the cell surface. The American Journal of Physiology 272:E864-9.

Fagard RH. 1992. Impact of different sports and training on cardiac structure and function. Cardiology clinics 10:241-256.

Fernandez-Caggiano M., Kamynina A., Francois AA., Prysyazhna O., Eykyn TR., Krasemann S., Crespo-Leiro MG., Vieites MG., Bianchi K., Morales V., Domenech N., Eaton P. 2020. Mitochondrial pyruvate carrier abundance mediates pathological cardiac hypertrophy. Nature Metabolism 2:1223-1231.

Fischer Y., Thomas J., Sevilla L., Muñoz P., Becker C., Holman G., Kozka IJ., Palacín M., Testar X., Kammermeier H., Zorzano A. 1997. Insulin-induced recruitment of glucose transporter 4 (GLUT4) and GLUT1 in isolated rat cardiac myocytes. Evidence of the existence of different intracellular GLUT4 vesicle populations. The Journal of Biological Chemistry 272:7085-7092.

Garvey WT., Maianu L., Zhu JH., Brechtel-Hook G., Wallace P., Baron AD. 1998. Evidence for defects in the trafficking and translocation of GLUT4 glucose transporters in skeletal muscle as a cause of human insulin resistance. The Journal of Clinical Investigation 101:2377-2386.

Gibb AA., Hill BG. 2018. Metabolic coordination of physiological and pathological cardiac remodeling. Circulation Research 123:107-128.

Glatz JFC., Nabben M., Young ME., Schulze PC., Taegtmeyer H., Luiken JJFP. 2020. Rebalancing cellular energy substrate metabolism to mend the failing heart. Biochimica et biophysica acta. Molecular basis of disease 1866:165579.

Gould GW., Brodsky FM., Bryant NJ. 2020. Building GLUT4 vesicles: CHC22 clathrin's human touch. Trends in Cell Biology.

Grundy SM., Barlow CE., Farrell SW., Vega GL., Haskell WL. 2012. Cardiorespiratory fitness and metabolic risk. The American Journal of Cardiology 109:988-993.

Gurley JM., Griesel BA., Olson AL. 2016. Increased skeletal muscle GLUT4 expression in obese mice after voluntary wheel running exercise is posttranscriptional. Diabetes 65:2911-2919.

Guzzardi MA., Hodson L., Guiducci L., Sanguinetti E., Di Cecco P., Liistro T., Vassalle C., Pardini S., Giorgetti L., Salvadori PA., Burchielle S., Iozzo O. 2014. Independent effects of circulating glucose, insulin and NEFA on cardiac triacylglycerol accumulation and myocardial insulin resistance in a swine model. Diabetologia 57:1937-1946.

Hafstad AD., Boardman N., Aasum E. 2015. How exercise may amend metabolic disturbances in diabetic cardiomyopathy. Antioxidants \& Redox Signaling 22:1587-1605.

Hafstad AD., Khalid AM., How O-J., Larsen TS., Aasum E. 2007. Glucose and insulin improve cardiac efficiency and postischemic functional recovery in perfused hearts from type 2 diabetic $(\mathrm{db} / \mathrm{db})$ mice. American Journal of Physiology. Endocrinology and Metabolism 292:E1288-94.

Hall JL., Sexton WL., Stanley WC. 1995. Exercise training attenuates the reduction in myocardial GLUT-4 in diabetic rats. Journal of Applied Physiology 78:76-81.

Hammer S., Snel M., Lamb HJ., Jazet IM., van der Meer RW., Pijl H., Meinders EA., Romijn JA., de Roos A., Smit JWA. 2008. Prolonged caloric restriction in obese patients with type 2 diabetes mellitus decreases myocardial triglyceride content and improves myocardial function. Journal of the American College of Cardiology 52:1006-1012.

PeerJ reviewing PDF | (2021:01:56957:1:1:NEW 15 Apr 2021) 
962 Hannan AL., Hing W., Simas V., Climstein M., Coombes JS., Jayasinghe R., Byrnes J., Furness

963

964

965

966

967

968

969

970

971

972

973

974

975

976

977

978

979

980

981

982

983

984

985

986

987

988

989

990

991

992

993

994

995

996

997

998

999

1000

1001

1002

1003

1004

1005

1006

1007
J. 2018. High-intensity interval training versus moderate-intensity continuous training within cardiac rehabilitation: a systematic review and meta-analysis. Open access journal of sports medicine 9:1-17.

Hare JL., Hordern MD., Leano R., Stanton T., Prins JB., Marwick TH. 2011. Application of an exercise intervention on the evolution of diastolic dysfunction in patients with diabetes mellitus: efficacy and effectiveness. Circulation. Heart Failure 4:441-449.

Harmon KG., Drezner JA., Wilson MG., Sharma S. 2014. Incidence of sudden cardiac death in athletes: a state-of-the-art review. Heart 100:1227-1234.

Hollekim-Strand SM., Bjørgaas MR., Albrektsen G., Tjønna AE., Wisløff U., Ingul CB. 2014. High-intensity interval exercise effectively improves cardiac function in patients with type 2 diabetes mellitus and diastolic dysfunction: a randomized controlled trial. Journal of the American College of Cardiology 64:1758-1760.

Holten MK., Zacho M., Gaster M., Juel C., Wojtaszewski JFP., Dela F. 2004. Strength training increases insulin-mediated glucose uptake, GLUT4 content, and insulin signaling in skeletal muscle in patients with type 2 diabetes. Diabetes 53:294-305.

Hordern MD., Coombes JS., Cooney LM., Jeffriess L., Prins JB., Marwick TH. 2009. Effects of exercise intervention on myocardial function in type 2 diabetes. Heart 95:1343-1349.

Hu L., Qiu C., Wang X., Xu M., Shao X., Wang Y. 2018. The association between diabetes mellitus and reduction in myocardial glucose uptake: a population-based 18F-FDG PET/CT study. BMC Cardiovascular Disorders 18:203.

Hue L., Taegtmeyer H. 2009. The Randle cycle revisited: a new head for an old hat. American Journal of Physiology. Endocrinology and Metabolism 297:E578-91.

Hussey SE., McGee SL., Garnham A., Wentworth JM., Jeukendrup AE., Hargreaves M. 2011. Exercise training increases adipose tissue GLUT4 expression in patients with type 2 diabetes. Diabetes, Obesity \& Metabolism 13:959-962.

Ingwall JS. 2009. Energy metabolism in heart failure and remodelling. Cardiovascular Research 81:412-419.

Iozzo P., Chareonthaitawee P., Dutka D., Betteridge DJ., Ferrannini E., Camici PG. 2002a. Independent association of type 2 diabetes and coronary artery disease with myocardial insulin resistance. Diabetes 51:3020-3024.

Iozzo P., Chareonthaitawee P., Rimoldi O., Betteridge DJ., Camici PG., Ferrannini E. 2002b. Mismatch between insulin-mediated glucose uptake and blood flow in the heart of patients with Type II diabetes. Diabetologia 45:1404-1409.

Itani SI., Ruderman NB., Schmieder F., Boden G. 2002. Lipid-induced insulin resistance in human muscle is associated with changes in diacylglycerol, protein kinase $\mathrm{C}$, and IkappaB-alpha. Diabetes 51:2005-2011.

Ivy JL. 2004. Muscle insulin resistance amended with exercise training: role of GLUT4 expression. Medicine and Science in Sports and Exercise 36:1207-1211.

Jacobs RA., Flück D., Bonne TC., Bürgi S., Christensen PM., Toigo M., Lundby C. 2013. Improvements in exercise performance with high-intensity interval training coincide with an increase in skeletal muscle mitochondrial content and function. Journal of Applied Physiology 115:785-793.

Jia G., Hill MA., Sowers JR. 2018. Diabetic cardiomyopathy: an update of mechanisms contributing to this clinical entity. Circulation Research 122:624-638.

Jones A., Olsen MZ., Perrild HJD., Willaing I. 2016. The psychological impact of living with 
1008

1009

1010

1011

1012

1013

1014

1015

1016

1017

1018

1019

1020

1021

1022

1023

1024

1025

1026

1027

1028

1029

1030

1031

1032

1033

1034

1035

1036

1037

1038

1039

1040

1041

1042

1043

1044

1045

1046

1047

1048

1049

1050

1051

1052

1053 diabetes: Descriptive findings from the DAWN2 study in Denmark. Primary care diabetes 10:83-86.

Karwi QG., Uddin GM., Ho KL., Lopaschuk GD. 2018. Loss of metabolic flexibility in the failing heart. Frontiers in cardiovascular medicine 5:68.

Kerr M., Dodd MS., Heather LC. 2017. The "Goldilocks zone" of fatty acid metabolism; to ensure that the relationship with cardiac function is just right. Clinical Science 131:20792094.

Khaw KT., Wareham N., Luben R., Bingham S., Oakes S., Welch A., Day N. 2001. Glycated haemoglobin, diabetes, and mortality in men in Norfolk cohort of european prospective investigation of cancer and nutrition (EPIC-Norfolk). BMJ (Clinical Research Ed.) 322:15-18.

Kim TT., Dyck JRB. 2016. The role of CD36 in the regulation of myocardial lipid metabolism. Biochimica et Biophysica Acta 1861:1450-1460.

Kirwan JP., del Aguila LF., Hernandez JM., Williamson DL., O’Gorman DJ., Lewis R., Krishnan RK. 2000. Regular exercise enhances insulin activation of IRS-1-associated PI3-kinase in human skeletal muscle. Journal of Applied Physiology 88:797-803.

Klein S., Coyle EF., Wolfe RR. 1994. Fat metabolism during low-intensity exercise in endurance-trained and untrained men. The American Journal of Physiology 267:E934-40.

Kokkinos P., Faselis C., Myers J., Pittaras A., Sui X., Zhang J., McAuley P., Kokkinos JP. 2014. Cardiorespiratory fitness and the paradoxical BMI-mortality risk association in male veterans. Mayo Clinic Proceedings 89:754-762.

Kraegen EW., Sowden JA., Halstead MB., Clark PW., Rodnick KJ., Chisholm DJ., James DE. 1993. Glucose transporters and in vivo glucose uptake in skeletal and cardiac muscle: fasting, insulin stimulation and immunoisolation studies of GLUT1 and GLUT4. The Biochemical Journal 295 ( Pt 1):287-293.

Lai L., Leone TC., Keller MP., Martin OJ., Broman AT., Nigro J., Kapoor K., Koves TR., Stevens R., Ilkayeva OR., Vega RB., Attie AD., Muoio DM., Kelly DP. 2014. Energy metabolic reprogramming in the hypertrophied and early stage failing heart: a multisystems approach. Circulation. Heart Failure 7:1022-1031.

Lamberts RR., Lingam SJ., Wang H-Y., Bollen IAE., Hughes G., Galvin IF., Bunton RW., Bahn A., Katare R., Baldi JC., Williams MJA., Saxena P., Coffey S., Jones PP. 2014. Impaired relaxation despite upregulated calcium-handling protein atrial myocardium from type 2 diabetic patients with preserved ejection fraction. Cardiovascular Diabetology 13:72.

Lancha A., López-Garrido S., Rodríguez A., Catalán V., Ramírez B., Valentí V., Moncada R., Silva C., Gil MJ., Salvador J., Fruhbeck G., Gomez-Ambrosi J. 2015. Expression of syntaxin 8 in visceral adipose tissue is increased in obese patients with type 2 diabetes and related to markers of insulin resistance and inflammation. Archives of Medical Research 46:47-53.

Lapp H., Bruegmann T., Malan D., Friedrichs S., Kilgus C., Heidsieck A., Sasse P. 2017. Frequency-dependent drug screening using optogenetic stimulation of human iPSCderived cardiomyocytes. Scientific Reports 7:9629.

Larsen HB., Sheel AW. 2015. The Kenyan runners. Scandinavian Journal of Medicine \& Science in Sports 25 Suppl 4:110-118.

Laukkanen JA., Rauramaa R., Salonen JT., Kurl S. 2007. The predictive value of cardiorespiratory fitness combined with coronary risk evaluation and the risk of cardiovascular and all-cause death. Journal of Internal Medicine 262:263-272.

Peer] reviewing PDF | (2021:01:56957:1:1:NEW 15 Apr 2021) 
1054 Lawler PR., Filion KB., Eisenberg MJ. 2011. Efficacy of exercise-based cardiac rehabilitation

1055

1056

1057

1058

1059

1060

1061

1062

1063

1064

1065

1066

1067

1068

1069

1070

1071

1072

1073

1074

1075

1076

1077

1078

1079

1080

1081

1082

1083

1084

1085

1086

1087

1088

1089

1090

1091

1092

1093

1094

1095

1096

1097

1098

1099 post-myocardial infarction: a systematic review and meta-analysis of randomized controlled trials. American Heart Journal 162:571-584.e2.

Leite SA., Monk AM., Upham PA., Bergenstal RM. 2009. Low cardiorespiratory fitness in people at risk for type 2 diabetes: early marker for insulin resistance. Diabetology \& metabolic syndrome 1:8.

Leto D., Saltiel AR. 2012. Regulation of glucose transport by insulin: traffic control of GLUT4. Nature Reviews. Molecular Cell Biology 13:383-396.

Levy WC., Cerqueira MD., Abrass IB., Schwartz RS., Stratton JR. 1993. Endurance exercise training augments diastolic filling at rest and during exercise in healthy young and older men. Circulation 88:116-126.

Liou K., Ho S., Fildes J., Ooi S-Y. 2016. High Intensity Interval versus Moderate Intensity Continuous Training in Patients with Coronary Artery Disease: A Meta-analysis of Physiological and Clinical Parameters. Heart, Lung \& Circulation 25:166-174.

Little JP., Gillen JB., Percival ME., Safdar A., Tarnopolsky MA., Punthakee Z., Jung ME., Gibala MJ. 2011. Low-volume high-intensity interval training reduces hyperglycemia and increases muscle mitochondrial capacity in patients with type 2 diabetes. Journal of Applied Physiology 111:1554-1560.

Liu Y., Steinbusch LKM., Nabben M., Kapsokalyvas D., van Zandvoort M., Schönleitner P., Antoons G., Simons PJ., Coumans WA., Geomini A. et al. 2017. Palmitate-Induced Vacuolar-Type H+-ATPase Inhibition Feeds Forward Into Insulin Resistance and Contractile Dysfunction. Diabetes 66:1521-1534.

Loimaala A., Groundstroem K., Rinne M., Nenonen A., Huhtala H., Vuori I. 2007. Exercise training does not improve myocardial diastolic tissue velocities in Type 2 diabetes. Cardiovascular Ultrasound 5:32.

Lopaschuk GD., Ussher JR. 2016. Evolving concepts of myocardial energy metabolism: more than just fats and carbohydrates. Circulation Research 119:1173-1176.

Lopaschuk GD., Ussher JR., Folmes CDL., Jaswal JS., Stanley WC. 2010. Myocardial fatty acid metabolism in health and disease. Physiological Reviews 90:207-258.

Luiken JJFP., Glatz JFC., Neumann D. 2015. Cardiac contraction-induced GLUT4 translocation requires dual signaling input. Trends in Endocrinology and Metabolism 26:404-410.

Luiken JJFP., Nabben M., Neumann D., Glatz JFC. 2020. Understanding the distinct subcellular trafficking of CD36 and GLUT4 during the development of myocardial insulin resistance. Biochimica et biophysica acta. Molecular basis of disease 1866:165775.

MacDonald TL., Pattamaprapanont P., Pathak P., Fernandez N., Freitas EC., Hafida S., Mitri J., Britton SL., Koch LG., Lessard SJ. 2020. Hyperglycaemia is associated with impaired muscle signalling and aerobic adaptation to exercise. Nature Metabolism 2:902-917.

Maiorana A., O’Driscoll G., Goodman C., Taylor R., Green D. 2002. Combined aerobic and resistance exercise improves glycemic control and fitness in type 2 diabetes. Diabetes Research and Clinical Practice 56:115-123.

Mazumder PK., O’Neill BT., Roberts MW., Buchanan J., Yun UJ., Cooksey RC., Boudina S., Abel ED. 2004. Impaired cardiac efficiency and increased fatty acid oxidation in insulinresistant ob/ob mouse hearts. Diabetes 53:2366-2374.

McConell GK., Sjøberg KA., Ceutz F., Gliemann L., Nyberg M., Hellsten Y., Frøsig C., Kiens B., Wojtaszewski JFP., Richter EA. 2020. Insulin-induced membrane permeability to glucose in human muscles at rest and following exercise. The Journal of Physiology 
1100

1101

1102

1103

1104

1105

1106

1107

1108

1109

1110

1111

1112

1113

1114

1115

1116

1117

1118

1119

1120

1121

1122

1123

1124

1125

1126

1127

1128

1129

1130

1131

1132

1133

1134

1135

1136

1137

1138

1139

1140

1141

1142

1143

1144

1145

598:303-315.

McGavock JM., Lingvay I., Zib I., Tillery T., Salas N., Unger R., Levine BD., Raskin P., Victor RG., Szczepaniak LS. 2007. Cardiac steatosis in diabetes mellitus: a 1H-magnetic resonance spectroscopy study. Circulation 116:1170-1175.

McGee SL., Sparling D., Olson A-L., Hargreaves M. 2006. Exercise increases MEF2- and GEF DNA-binding activity in human skeletal muscle. The FASEB Journal 20:348-349.

McMullen JR., Shioi T., Zhang L., Tarnavski O., Sherwood MC., Kang PM., Izumo S. 2003. Phosphoinositide 3-kinase(p110alpha) plays a critical role for the induction of physiological, but not pathological, cardiac hypertrophy. Proceedings of the National Academy of Sciences of the United States of America 100:12355-12360.

van der Meer RW., Rijzewijk LJ., Diamant M., Hammer S., Schär M., Bax JJ., Smit JWA., Romijn JA., de Roos A., Lamb HJ. 2008. The ageing male heart: myocardial triglyceride content as independent predictor of diastolic function. European Heart Journal 29:15161522.

van der Meer RW., Rijzewijk LJ., de Jong HWAM., Lamb HJ., Lubberink M., Romijn JA., Bax JJ., de Roos A., Kamp O., Paulus WJ. et al. 2009. Pioglitazone improves cardiac function and alters myocardial substrate metabolism without affecting cardiac triglyceride accumulation and high-energy phosphate metabolism in patients with well-controlled type 2 diabetes mellitus. Circulation 119:2069-2077.

Meex RCR., Schrauwen-Hinderling VB., Moonen-Kornips E., Schaart G., Mensink M., Phielix E., van de Weijer T., Sels J-P., Schrauwen P., Hesselink MKC. 2010. Restoration of muscle mitochondrial function and metabolic flexibility in type 2 diabetes by exercise training is paralleled by increased myocellular fat storage and improved insulin sensitivity. Diabetes 59:572-579.

Milanović Z., Sporiš G., Weston M. 2015. Effectiveness of High-Intensity Interval Training (HIT) and Continuous Endurance Training for VO2max Improvements: A Systematic Review and Meta-Analysis of Controlled Trials. Sports medicine (Auckland, N.Z.) 45:1469-1481.

Mills RJ., Parker BL., Quaife-Ryan GA., Voges HK., Needham EJ., Bornot A., Ding M., Andersson H., Polla M., Elliott DA., Drowley L., Clausen M., Plowright AT., Barett IP., Wang Q-D., James DE., Porrello ER., Hudson JE. 2019. Drug Screening in Human PSCCardiac Organoids Identifies Pro-proliferative Compounds Acting via the Mevalonate Pathway. Cell Stem Cell 24:895-907.e6.

Mishra PK., Awe O., Metreveli N., Qipshidze N., Joshua IG., Tyagi SC. 2011. Exercise mitigates homocysteine - $\beta 2$-adrenergic receptor interactions to ameliorate contractile dysfunction in diabetes. International journal of physiology, pathophysiology and pharmacology 3:97-106.

Moholdt T., Aamot IL., Granøien I., Gjerde L., Myklebust G., Walderhaug L., Brattbakk L., Hole T., Graven T., Stølen TO., Amundsen BH., Mølmen-Hanse, HE., Støylen A., Wisløff U., Slørdahl SA.2012. Aerobic interval training increases peak oxygen uptake more than usual care exercise training in myocardial infarction patients: a randomized controlled study. Clinical Rehabilitation 26:33-44.

Morris JN., Raffle PA. 1954. Coronary heart disease in transport workers; a progress report. British journal of industrial medicine 11:260-264.

Mueckler M., Thorens B. 2013. The SLC2 (GLUT) family of membrane transporters. Molecular aspects of medicine 34:121-138. 
1146 Murray AJ., Anderson RE., Watson GC., Radda GK., Clarke K. 2004. Uncoupling proteins in

Murtaza G., Virk HUH., Khalid M., Lavie CJ., Ventura H., Mukherjee D., Ramu V., Bhogal S., Kumar G., Shanmugasundaram M., Paul TK. 2019. Diabetic cardiomyopathy - A comprehensive updated review. Progress in Cardiovascular Diseases 62:315-326.

Neri Serneri GG., Boddi M., Modesti PA., Cecioni I., Coppo M., Padeletti L., Michelucci A., Colella A., Galanti G. 2001. Increased cardiac sympathetic activity and insulin-like growth factor-I formation are associated with physiological hypertrophy in athletes. Circulation Research 89:977-982.

Nicolino A., Longobardi G., Furgi G., Rossi M., Zoccolillo N., Ferrara N., Rengo F. 1995. Left ventricular diastolic filling in diabetes mellitus with and without hypertension. American Journal of Hypertension 8:382-389.

de Noronha SV., Sharma S., Papadakis M., Desai S., Whyte G., Sheppard MN. 2009. Aetiology of sudden cardiac death in athletes in the United Kingdom: a pathological study. Heart 95:1409-1414.

O’Gorman DJ., Karlsson HKR., McQuaid S., Yousif O., Rahman Y., Gasparro D., Glund S., Chibalin AV., Zierath JR., Nolan JJ. 2006. Exercise training increases insulin-stimulated glucose disposal and GLUT4 (SLC2A4) protein content in patients with type 2 diabetes. Diabetologia 49:2983-2992.

O’Neill HM., Maarbjerg SJ., Crane JD., Jeppesen J., Jørgensen SB., Schertzer JD., Shyroka O., Kiens B., van Denderen BJ., Tarnopolsky MA., Kemp BE., Richter EA, Steinberg GR. 2011. AMP-activated protein kinase (AMPK) beta1beta2 muscle null mice reveal an essential role for AMPK in maintaining mitochondrial content and glucose uptake during exercise. Proceedings of the National Academy of Sciences of the United States of America 108:16092-16097.

Osborn BA., Daar JT., Laddaga RA., Romano FD., Paulson DJ. 1997. Exercise training increases sarcolemmal GLUT-4 protein and mRNA content in diabetic heart. Journal of Applied Physiology 82:828-834.

Ouwens DM., Boer C., Fodor M., de Galan P., Heine RJ., Maassen JA., Diamant M. 2005. Cardiac dysfunction induced by high-fat diet is associated with altered myocardial insulin signalling in rats. Diabetologia 48:1229-1237.

Ouwens DM., Diamant M., Fodor M., Habets DDJ., Pelsers MMAL., El Hasnaoui M., Dang ZC., van den Brom CE., Vlasblom R., Rietdijk A., Boer C., Coort SLM., Glatz JFC., Luiken JJFP. 2007. Cardiac contractile dysfunction in insulin-resistant rats fed a high-fat diet is associated with elevated CD36-mediated fatty acid uptake and esterification. Diabetologia 50:1938-1948.

Palabiyik O., Karaca A., Taştekin E., Yamasan BE., Tokuç B., Sipahi T., Vardar SA. 2016. The Effect of a High-Protein Diet and Exercise on Cardiac AQP7 and GLUT4 Gene Expression. Biochemical Genetics 54:731-745.

Parikh SS., Blackwell DJ., Gomez-Hurtado N., Frisk M., Wang L., Kim K., Dahl CP., Fiane A., Tønnessen T., Kryshtal DO. et al. 2017. Thyroid and Glucocorticoid Hormones Promote Functional T-Tubule Development in Human-Induced Pluripotent Stem Cell-Derived Cardiomyocytes. Circulation Research 121:1323-1330.

Park S-Y., Cho Y-R., Kim H-J., Higashimori T., Danton C., Lee M-K., Dey A., Rothermel B., Kim Y-B., Kalinowski A., Russell KS., Kim, JK. 2005. Unraveling the temporal pattern of diet-induced insulin resistance in individual organs and cardiac dysfunction in 
1192

1193

1194

1195

1196

1197

1198

1199

1200

1201

1202

1203

1204

1205

1206

1207

1208

1209

1210

1211

1212

1213

1214

1215

1216

1217

1218

1219

1220

1221

1222

1223

1224

1225

1226

1227

1228

1229

1230

1231

1232

1233

1234

1235

1236

1237

C57BL/6 mice. Diabetes 54:3530-3540.

Pearson MJ., Mungovan SF., Smart NA. 2017. Effect of exercise on diastolic function in heart failure patients: a systematic review and meta-analysis. Heart failure reviews 22:229242.

Pereira L., Matthes J., Schuster I., Valdivia HH., Herzig S., Richard S., Gómez AM. 2006. Mechanisms of $[\mathrm{Ca} 2+]$ i transient decrease in cardiomyopathy of $\mathrm{db} / \mathrm{db}$ type 2 diabetic mice. Diabetes 55:608-615.

Pillon NJ., Loos RJF., Marshall SM., Zierath JR. 2021. Metabolic consequences of obesity and type 2 diabetes: Balancing genes and environment for personalized care. Cell 184:15301544.

Plomgaard P., Bouzakri K., Krogh-Madsen R., Mittendorfer B., Zierath JR., Pedersen BK. 2005. Tumor necrosis factor-alpha induces skeletal muscle insulin resistance in healthy human subjects via inhibition of Akt substrate 160 phosphorylation. Diabetes 54:2939-2945.

Poirier P., Bogaty P., Garneau C., Marois L., Dumesnil JG. 2001. Diastolic dysfunction in normotensive men with well-controlled type 2 diabetes: importance of maneuvers in echocardiographic screening for preclinical diabetic cardiomyopathy. Diabetes Care 24:5-10.

Ponticos M., Lu QL., Morgan JE., Hardie DG., Partridge TA., Carling D. 1998. Dual regulation of the AMP-activated protein kinase provides a novel mechanism for the control of creatine kinase in skeletal muscle. The EMBO Journal 17:1688-1699.

Poulsen MK., Henriksen JE., Dahl J., Johansen A., Gerke O., Vach W., Haghfelt T., HøilundCarlsen PF., Beck-Nielsen H., Møller JE. 2010. Left ventricular diastolic function in type 2 diabetes mellitus: prevalence and association with myocardial and vascular disease. Circulation. Cardiovascular Imaging 3:24-31.

Randle PJ., Garland PB., Hales CN., Newsholme EA. 1963. The glucose fatty-acid cycle. Its role in insulin sensitivity and the metabolic disturbances of diabetes mellitus. The Lancet 1:785-789.

Richter EA. 2020. Is GLUT4 translocation the answer to exercise stimulated muscle glucose uptake? American Journal of Physiology. Endocrinology and Metabolism.

Richter EA., Hargreaves M. 2013. Exercise, GLUT4, and skeletal muscle glucose uptake. Physiological Reviews 93:993-1017.

Rijzewijk LJ., van der Meer RW., Lamb HJ., de Jong HWAM., Lubberink M., Romijn JA., Bax JJ., de Roos A., Twisk JW., Heine RJ., Lammertsma AA., Smit JWA., Diamant M. 2009. Altered myocardial substrate metabolism and decreased diastolic function in nonischemic human diabetic cardiomyopathy: studies with cardiac positron emission tomography and magnetic resonance imaging. Journal of the American College of Cardiology 54:15241532.

Rijzewijk LJ., van der Meer RW., Smit JWA., Diamant M., Bax JJ., Hammer S., Romijn JA., de Roos A., Lamb HJ. 2008. Myocardial steatosis is an independent predictor of diastolic dysfunction in type 2 diabetes mellitus. Journal of the American College of Cardiology 52:1793-1799.

Ritterhoff J., Tian R. 2017. Metabolism in cardiomyopathy: every substrate matters. Cardiovascular Research 113:411-421.

Rognmo Ø., Moholdt T., Bakken H., Hole T., Mølstad P., Myhr NE., Grimsmo J., Wisløff U. 2012. Cardiovascular risk of high- versus moderate-intensity aerobic exercise in coronary heart disease patients. Circulation 126:1436-1440. 
1238 Röhling M., Herder C., Roden M., Stemper T., Müssig K. 2016. Effects of Long-Term Exercise

1239

1240

1241

1242

1243

1244

1245

1246

1247

1248

1249

1250

1251

1252

1253

1254

1255

1256

1257

1258

1259

1260

1261

1262

1263

1264

1265

1266

1267

1268

1269

1270

1271

1272

1273

1274

1275

1276

1277

1278

1279

1280

1281

1282

1283
Interventions on Glycaemic Control in Type 1 and Type 2 Diabetes: a Systematic Review. Experimental and Clinical Endocrinology \& Diabetes 124:487-494.

Ronaldson-Bouchard K., Ma SP., Yeager K., Chen T., Song L., Sirabella D., Morikawa K., Teles D., Yazawa M., Vunjak-Novakovic G. 2018. Advanced maturation of human cardiac tissue grown from pluripotent stem cells. Nature 556:239-243.

Rubler S., Dlugash J., Yuceoglu YZ., Kumral T., Branwood AW., Grishman A. 1972. New type of cardiomyopathy associated with diabetic glomerulosclerosis. The American Journal of Cardiology 30:595-602.

Santacruz L., Arciniegas AJL., Darrabie M., Mantilla JG., Baron RM., Bowles DE., Mishra R., Jacobs DO. 2017. Hypoxia decreases creatine uptake in cardiomyocytes, while creatine supplementation enhances HIF activation. Physiological reports 5.

Santalucía T., Camps M., Castelló A., Muñoz P., Nuel A., Testar X., Palacin M., Zorzano A. 1992. Developmental regulation of GLUT-1 (erythroid/Hep G2) and GLUT-4 (muscle/fat) glucose transporter expression in rat heart, skeletal muscle, and brown adipose tissue. Endocrinology 130:837-846.

Scalzo RL., Peltonen GL., Binns SE., Shankaran M., Giordano GR., Hartley DA., Klochak AL., Lonac MC., Paris HLR., Szallar SE., Wood LM., Peelor FF., Holmes WE., Hellersein MCK., Bell C., Hamilton KL., Miller BF. 2014. Greater muscle protein synthesis and mitochondrial biogenesis in males compared with females during sprint interval training. The FASEB Journal 28:2705-2714.

Schannwell CM., Schneppenheim M., Perings S., Plehn G., Strauer BE. 2002. Left ventricular diastolic dysfunction as an early manifestation of diabetic cardiomyopathy. Cardiology 98:33-39.

Schaun MI., Marschner RA., Peres TR., Markoski MM., Lehnen AM. 2017. Aerobic training prior to myocardial infarction increases cardiac GLUT4 and partially preserves heart function in spontaneously hypertensive rats. Applied Physiology, Nutrition, and Metabolism 42:334-337.

Scheuermann-Freestone M., Madsen PL., Manners D., Blamire AM., Buckingham RE., Styles P., Radda GK., Neubauer S., Clarke K. 2003. Abnormal cardiac and skeletal muscle energy metabolism in patients with type 2 diabetes. Circulation 107:3040-3046.

Schlaepfer IR., Pulawa LK., Ferreira LDMC-B., James DE., Capell WH., Eckel RH. 2003. Increased expression of the SNARE accessory protein Munc18c in lipid-mediated insulin resistance. Journal of Lipid Research 44:1174-1181.

Schrauwen-Hinderling VB., Meex RCR., Hesselink MKC., van de Weijer T., Leiner T., Schär M., Lamb HJ., Wildberger JE., Glatz JFC., Schrauwen P., Kooi ME. 2011. Cardiac lipid content is unresponsive to a physical activity training intervention in type 2 diabetic patients, despite improved ejection fraction. Cardiovascular Diabetology 10:47.

Schwenk RW., Dirkx E., Coumans WA., Bonen A., Klip A., Glatz JFC., Luiken JJFP. 2010. Requirement for distinct vesicle-associated membrane proteins in insulin- and AMPactivated protein kinase (AMPK)-induced translocation of GLUT4 and CD36 in cultured cardiomyocytes. Diabetologia 53:2209-2219.

Searls YM., Smirnova IV., Fegley BR., Stehno-Bittel L. 2004. Exercise attenuates diabetesinduced ultrastructural changes in rat cardiac tissue. Medicine and Science in Sports and Exercise 36:1863-1870.

Semeniuk LM., Kryski AJ., Severson DL. 2002. Echocardiographic assessment of cardiac 
1284

1285

1286

1287

1288

1289

1290

1291

1292

1293

1294

1295

1296

1297

1298

1299

1300

1301

1302

1303

1304

1305

1306

1307

1308

1309

1310

1311

1312

1313

1314

1315

1316

1317

1318

1319

1320

1321

1322

1323

1324

1325

1326

1327

1328

1329

function in diabetic $\mathrm{db} / \mathrm{db}$ and transgenic $\mathrm{db} / \mathrm{db}$-hGLUT4 mice. American Journal of Physiology. Heart and Circulatory Physiology 283:H976-82.

Seo DY., Ko JR., Jang JE., Kim TN., Youm JB., Kwak H-B., Bae JH., Kim AH., Ko KS., Rhee BD., Han J. 2019. Exercise as A Potential Therapeutic Target for Diabetic Cardiomyopathy: Insight into the Underlying Mechanisms. International Journal of Molecular Sciences 20.

Shao D., Tian R. 2015. Glucose transporters in cardiac metabolism and hypertrophy. Comprehensive Physiology 6:331-351.

Sharma V., Dhillon P., Wambolt R., Parsons H., Brownsey R., Allard MF., McNeill JH. 2008. Metoprolol improves cardiac function and modulates cardiac metabolism in the streptozotocin-diabetic rat. American Journal of Physiology. Heart and Circulatory Physiology 294:H1609-20.

Shiba Y., Gomibuchi T., Seto T., Wada Y., Ichimura H., Tanaka Y., Ogasawara T., Okada K., Shiba N., Sakamoto K., Ido D., Shiina T., Ohkura M., Nakai J., Uno N., Kazuki Y., Oshimura M., Minami I., Ikeda U. 2016. Allogeneic transplantation of iPS cell-derived cardiomyocytes regenerates primate hearts. Nature 538:388-391.

Shipp JC., Opie LH., Challoner D. 1961. Fatty acid and glucose metabolism in the perfused heart. Nature 189:1018-1019.

Sigal RJ., Kenny GP., Boulé NG., Wells GA., Prud'homme D., Fortier M., Reid RD., Tulloch H., Coyle D., Phillips P., Jennings A., Jaffrey J. 2007. Effects of aerobic training, resistance training, or both on glycemic control in type 2 diabetes: a randomized trial. Annals of Internal Medicine 147:357-369.

Sindiani M., Eliakim A., Segev D., Meckel Y. 2017. The effect of two different interval-training programmes on physiological and performance indices. European journal of sport science 17:830-837.

Son N-H., Basu D., Samovski D., Pietka TA., Peche VS., Willecke F., Fang X., Yu S-Q., Scerbo D., Chang HR., Sun F., Bagdasarov S., Drosatos K., Yeh ST., Mullick AE., Shogi KI., Gumaste N., Kim KJ., Huggins L-A., Lhakhang T., Abumrad NA., Goldber IJ. 2018. Endothelial cell CD36 optimizes tissue fatty acid uptake. The Journal of Clinical Investigation. 128: 4329-4342.

Stølen TO., Høydal MA., Kemi OJ., Catalucci D., Ceci M., Aasum E., Larsen T., Rolim N., Condorelli G., Smith GL., U.Wisloff. 2009. Interval training normalizes cardiomyocyte function, diastolic $\mathrm{Ca} 2+$ control, and $\mathrm{SR} \mathrm{Ca} 2+$ release synchronicity in a mouse model of diabetic cardiomyopathy. Circulation Research 105:527-536.

Swift DL., McGee JE., Earnest CP., Carlisle E., Nygard M., Johannsen NM. 2018. The effects of exercise and physical activity on weight loss and maintenance. Progress in Cardiovascular Diseases 61:206-213.

Sylow L., Møller LLV., Kleinert M., D’Hulst G., De Groote E., Schjerling P., Steinberg GR., Jensen TE., Richter EA. 2017. Rac1 and AMPK account for the majority of muscle glucose uptake stimulated by ex vivo contraction but not in vivo exercise. Diabetes 66:1548-1559.

Taegtmeyer H., Beauloye C., Harmancey R., Hue L. 2013. Insulin resistance protects the heart from fuel overload in dysregulated metabolic states. American Journal of Physiology. Heart and Circulatory Physiology 305:H1693-7.

Tan Y., Zhang Z., Zheng C., Wintergerst KA., Keller BB., Cai L. 2020. Mechanisms of diabetic cardiomyopathy and potential therapeutic strategies: preclinical and clinical evidence. 
1330

1331

1332

1333

1334

1335

1336

1337

1338

1339

1340

1341

1342

1343

1344

1345

1346

1347

1348

1349

1350

1351

1352

1353

1354

1355

1356

1357

1358

1359

1360

1361

1362

1363

1364

1365

1366

1367

1368

1369

1370

1371

1372

1373

1374

1375

Nature Reviews. Cardiology 17:585-607.

Taylor R. 2019. Calorie restriction for long-term remission of type 2 diabetes. Clinical Medicine 19:37-42.

Taylor RS., Long L., Mordi IR., Madsen MT., Davies EJ., Dalal H., Rees K., Singh SJ., Gluud C., Zwisler A-D. 2019. Exercise-Based Rehabilitation for Heart Failure: Cochrane Systematic Review, Meta-Analysis, and Trial Sequential Analysis. JACC. Heart failure 7:691-705.

Thyfault JP., Bergouignan A. 2020. Exercise and metabolic health: beyond skeletal muscle. Diabetologia.

Tomas-Carus P., Ortega-Alonso A., Pietilainen KH., Santos V., Goncalves H., Ramos J., Raimundo A. 2016. A randomized controlled trial on the effects of combined aerobicresistance exercise on muscle strength and fatigue, glycemic control and health-related quality of life of type 2 diabetes patients. The Journal of Sports Medicine and Physical Fitness 56:572-578.

Trachsel LD., Ryffel CP., De Marchi S., Seiler C., Brugger N., Eser P., Wilhelm M. 2018. Exercise-induced cardiac remodeling in non-elite endurance athletes: Comparison of 2tiered and 4-tiered classification of left ventricular hypertrophy. Plos One 13:e0193203.

Utz W., Engeli S., Haufe S., Kast P., Hermsdorf M., Wiesner S., Pofahl M., Traber J., Luft FC., Boschmann M., Schulz-Menger J., Jordan J. 2011. Myocardial steatosis, cardiac remodelling and fitness in insulin-sensitive and insulin-resistant obese women. Heart 97:1585-1589.

Verboven M., Van Ryckeghem L., Belkhouribchia J., Dendale P., Eijnde BO., Hansen D., Bito V. 2019. Effect of exercise intervention on cardiac function in type 2 diabetes mellitus: A systematic review. Sports medicine (Auckland, N.Z.) 49:255-268.

Wang H., Bei Y., Lu Y., Sun W., Liu Q., Wang Y., Cao Y., Chen P., Xiao J., Kong X. 2015. Exercise Prevents Cardiac Injury and Improves Mitochondrial Biogenesis in Advanced Diabetic Cardiomyopathy with PGC-1 $\alpha$ and Akt Activation. Cellular Physiology and Biochemistry 35:2159-2168.

Wende AR., Schell JC., Ha C-M., Pepin ME., Khalimonchuk O., Schwertz H., Pereira RO., Brahma MK., Tuinei J., Contreras-Ferrat A., Wang L., Andrizzi CA., Olsen CD., Bradley WE., Dell'Italia LJ., Dillman WH., Litwin SE., Abel ED. 2020. Maintaining myocardial glucose utilization in diabetic cardiomyopathy accelerates mitochondrial dysfunction. Diabetes. 69:2094-2111.

Wheatley CM., Rattigan S., Richards SM., Barrett EJ., Clark MG. 2004. Skeletal muscle contraction stimulates capillary recruitment and glucose uptake in insulin-resistant obese Zucker rats. American Journal of Physiology. Endocrinology and Metabolism 287:E8049.

Wisløff U., Loennechen JP., Currie S., Smith GL., Ellingsen Ø. 2002. Aerobic exercise reduces cardiomyocyte hypertrophy and increases contractility, Ca2+ sensitivity and SERCA-2 in rat after myocardial infarction. Cardiovascular Research 54:162-174.

Wisløff U., Støylen A., Loennechen JP., Bruvold M., Rognmo Ø., Haram PM., Tjønna AE., Helgerud J., Slørdahl SA., Lee SJ., Videm V., Bye A., Smith GL., Najjar SM., Ellingsen Ø., Skjaerpe T. 2007. Superior cardiovascular effect of aerobic interval training versus moderate continuous training in heart failure patients: a randomized study. Circulation 115:3086-3094.

Wojtaszewski JF., Hansen BF., Gade., Kiens B., Markuns JF., Goodyear LJ., Richter EA. 2000.

PeerJ reviewing PDF | (2021:01:56957:1:1:NEW 15 Apr 2021) 
1376 Insulin signaling and insulin sensitivity after exercise in human skeletal muscle. Diabetes 1377 49:325-331.

1378 Zorzano A., Palacín M., Gumà A. 2005. Mechanisms regulating GLUT4 glucose transporter 1379 expression and glucose transport in skeletal muscle. Acta Physiologica Scandinavica $1380 \quad 183: 43-58$.

1381 
Figure 1

Figure 1 Mechanisms of diabetic cardiomyopathy

A range of contributory factors in the development of diabetic cardiomyopathy have been proposed. These include lipotoxicity, impaired insulin signalling, accumulation of advanced glycation end products, ER and oxidative stress. We focus on metabolic disturbance, specifically defects in the GLUT4 glucose transport system.

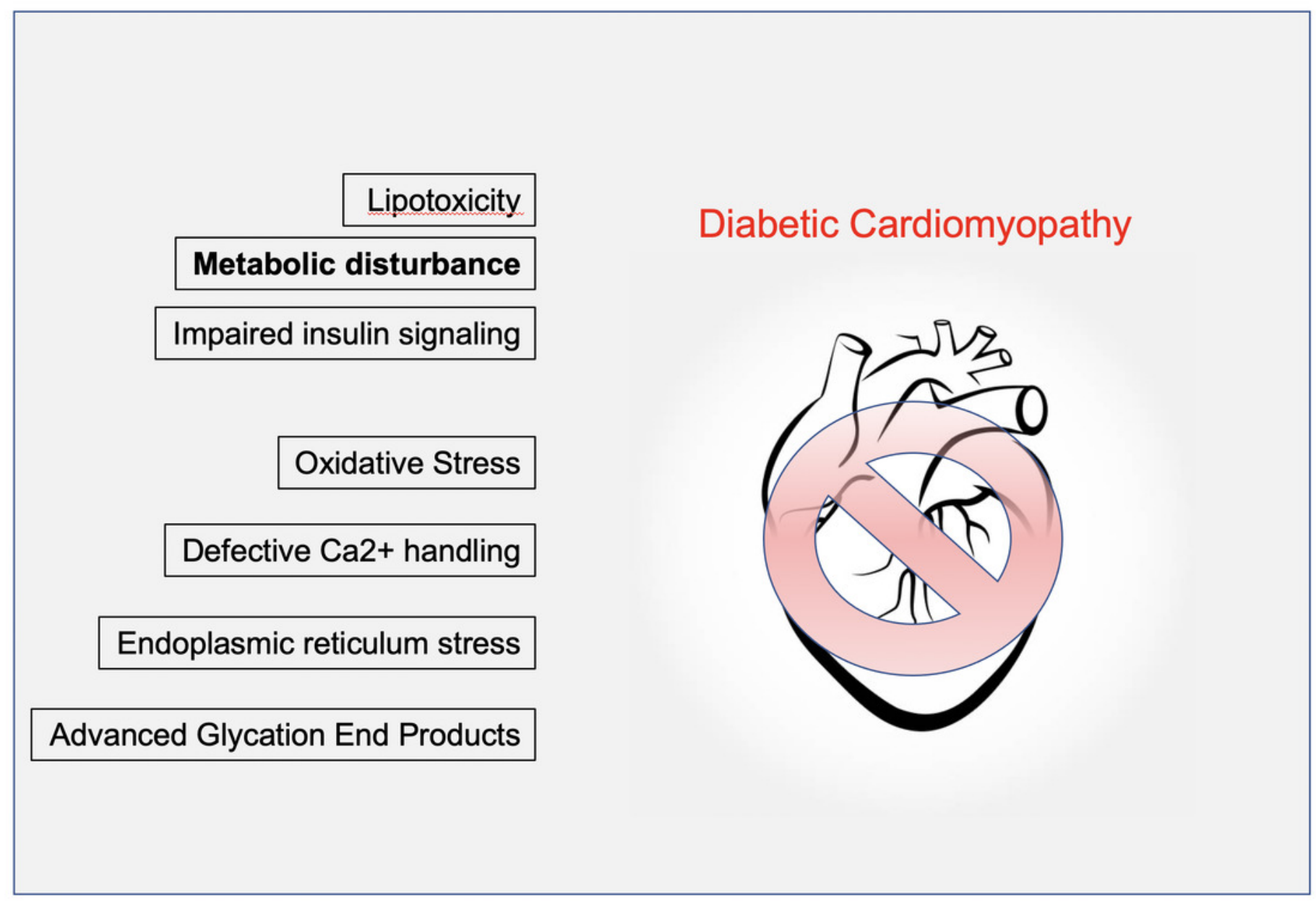




\section{Figure 2}

Figure 2 Trafficking of GLUT4 and CD36 in cardiomyocytes

In the well-perfused healthy heart $>95 \%$ of ATP is produced by oxidative phosphorylation and $60-90 \%$ of this is derived from metabolism of fatty acids which is the predominantly available substrate. The extraordinary high energetic demand of the heart is underpinned by an ability to adjust substrate preference to match the energetic demand with the levels of prevailing substrate in the circulation. The ability to 'shift' substrate preference is beneficial (Ritterhoff $\&$ Tian, 2017) . For both fatty acids and glucose, flux analysis supports the contention that it is the delivery across the plasma membrane (PM) that controls the flux through the respective metabolic pathways. CD36 is a multifunctional protein which mediates $\sim 70 \%$ of the uptake of fatty acids in cardiomyocytes. GLUT4 is the predominant glucose transporter in cardiomyocytes (Abel, 2004; Luiken et al., 2020) . Both recycle between intracellular stores and the PM. In response to insulin or contraction, PM levels of CD36 and GLUT4 increase. [Note that different populations of intracellular GLUT4 are mobilised by insulin or contraction, but this is not shown here for simplicity]. Once inside the cell, fatty acids are rapidly converted into fatty acyl CoA by fatty acyl CoA synthase which are then substrates for $\beta$ oxidation in mitochondria. Similarly, glucose is rapidly converted to glucose-6-phosphate and metabolised to pyruvate in the cytosol and then enters the TCA cycle. Reduced expression of the mitochondrial pyruvate carrier proteins is associated with cardiac hypertrophy in human heart (Fernandez-Caggiano et al., 2020). Hence, cardiomyocyte metabolism is considered to be highly adaptive and tightly regulated by hormonal and contraction signals, coupling fuel use with available substrate and metabolic need. 


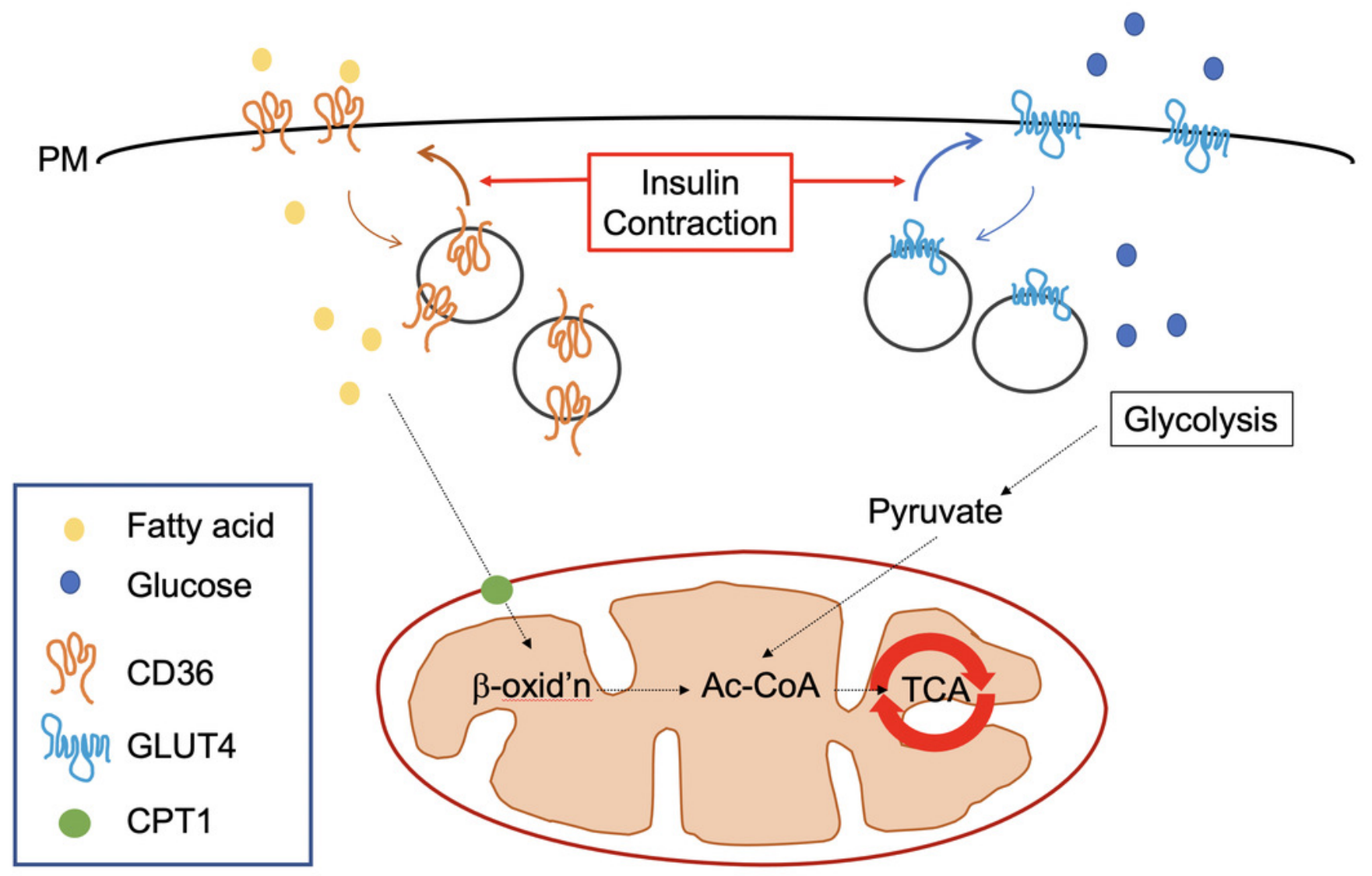




\section{Figure 3}

Figure 3 Possible metabolic abnormalities leading to diastolic dysfunction

Three possible mechanisms are discussed which may link impaired cardiomyocyte energy metabolism to diastolic dysfunction. These include changes in the balance of fuel use. Increased fatty acid transport and fatty acid cytosolic levels are associated with over-feeding and may lead to insulin resistance and starve the heart of the glucose that it needs to rapidly and efficiently generate the ATP that powers excitation contraction coupling. A high fat diet is known to increase cell surface CD36 levels and reduce levels of GLUT4 at the PM, giving rise to increased fatty acid metabolism and the accumulation of toxic lipid metabolites such as ceramide [1]. Impaired insulin signalling has also been posited as underlying diabetic cardiomyopathy [2]; ceramide is also known to inhibit insulin signalling pathways (see text). Although a relatively small contributor to total cardiac metabolism in the healthy heart (Ingwall, 2009; Ritterhoff \& Tian, 2017) , in this review, we focus on reduced glucose uptake and decreased levels of GLUT4 [3] as a key underpinning mechanism in diabetic cardiomyopathy and consider whether restoration of GLUT4 levels may be a useful therapeutic intervention. 


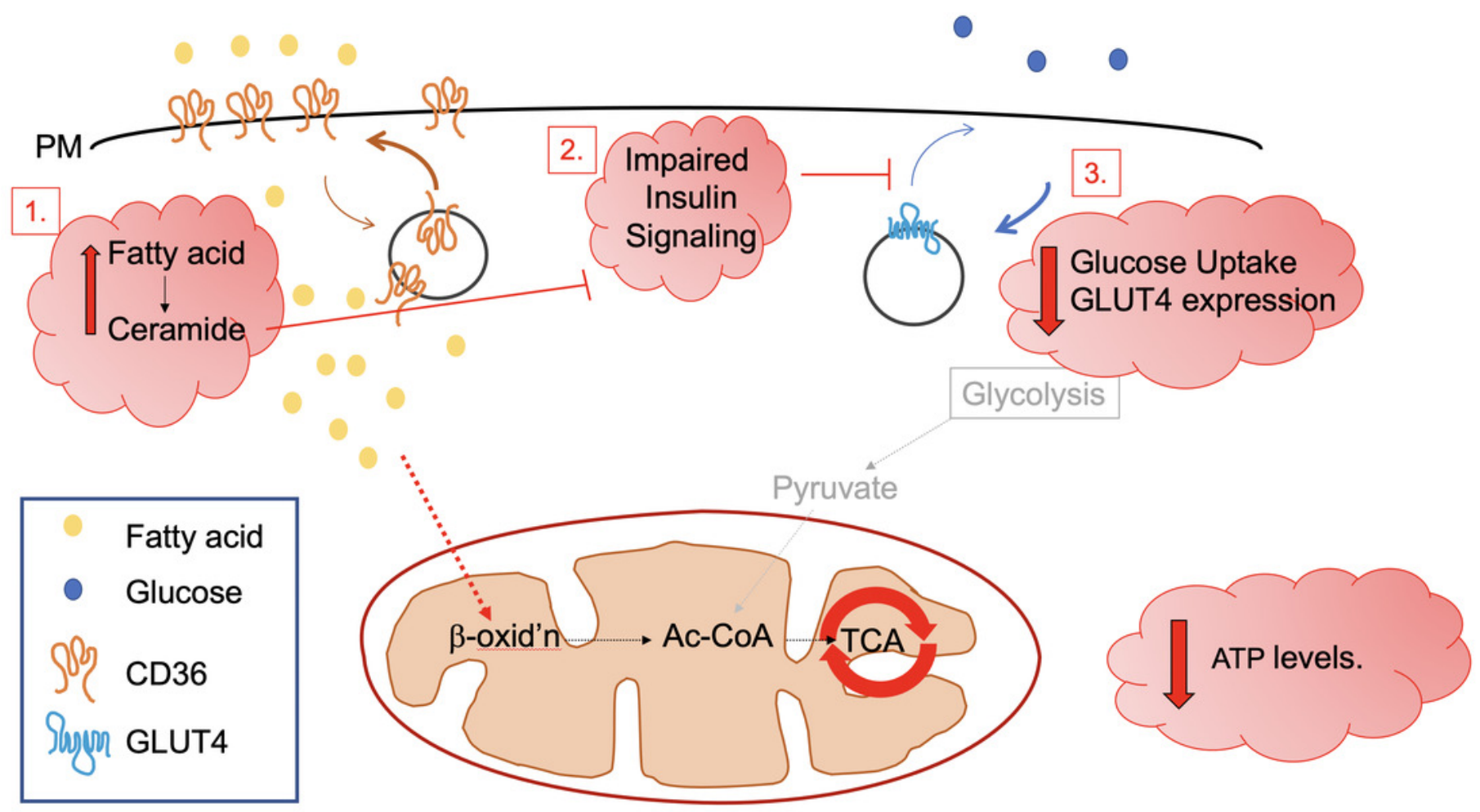




\section{Figure 4}

Figure 4 Key mechanisms through which exercise may improve cardiac function in DCM.

Shown are several mechanisms through which exercise training may alleviate cardiac dysfunction associated with DCM. Firstly, exercise may normalise cardiac metabolism, which could directly enhance cardiac contractile function through increasing ATP availability. Similarly, exercise has been shown to alleviate impairments in cardiomyocyte calcium handling, which could directly enhance contractile function through more efficient use of ATP. It is unclear if these adaptive mechanisms occur independently or if there is a functional link. Finally, general global benefits of exercise training such as weight loss could reduce the burden on the diabetic heart, thus improving function. Please note that we have limited our discussion to what we consider to be key potential mechanisms; see main text for further details.

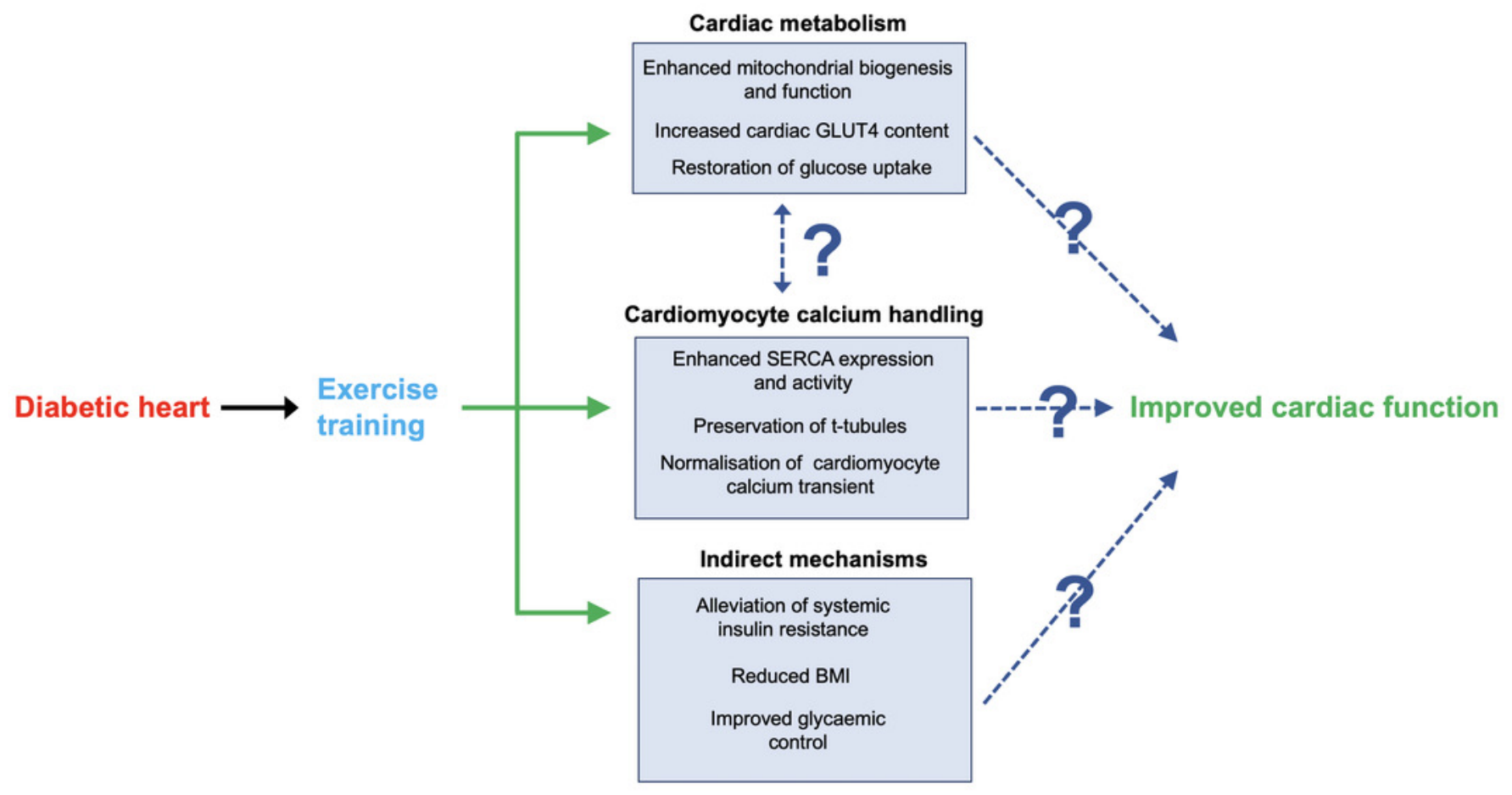

